\title{
Forebrain oscillators ticking with different clock hands
}

\author{
Céline A. Feillet, ${ }^{\mathrm{a}, 1}$ Jorge Mendoza, ${ }^{\mathrm{a}, 1}$ Urs Albrecht, ${ }^{\mathrm{b}}$ Paul Pévet, ${ }^{\mathrm{a}}$ and Etienne Challet ${ }^{\mathrm{a}, *}$ \\ ${ }^{a}$ Department of Neurobiology of Rhythms, Institute of Cellular and Integrative Neurosciences, IFR37, University Louis Pasteur, \\ Centre National de la Recherche Scientifique, 5 rue Blaise Pascal, 67084 Strasbourg, France \\ ${ }^{\mathrm{b}}$ Department of Medicine, Division of Biochemistry, University of Fribourg, 1700 Fribourg, Switzerland
}

\begin{abstract}
Clock proteins like PER1 and PER2 are expressed in the brain, but little is known about their functionality outside the main suprachiasmatic clock. Here we show that PER1 and PER2 were neither uniformly present nor identically phased in forebrain structures of mice fed ad libitum. Altered expression of the clock gene Cry1 was observed in respective Per1 or Per2 mutants. In response to hypocaloric feeding, PERs timing was not markedly affected in few forebrain structures (hippocampus). In most other forebrain oscillators, including those expressing only PER1 (e.g., dorsomedial hypothalamus), PER2 (e.g., paraventricular hypothalamus) or both (e.g., paraventricular thalamus), PER1 was up-regulated and PER2 largely phase-advanced. Cry 1 expression was selectively modified in the forebrain of Per mutants challenged with hypocaloric feeding. Our results suggest that there is not one single cerebral clock, but a system of multiple brain oscillators ticking with different clock hands and differentially sensitive to nutritional cues.
\end{abstract}

Keywords: Circadian rhythm; Clock proteins; Period; Cryptochrome; DBP; Per mutant

\section{Introduction}

In mammals, the master circadian clock, which synchronizes physiology and behavior, resides in the suprachiasmatic nuclei of the hypothalamus $(\mathrm{SCN})$ and is reset by light-dark cycles (Takahashi et al., 2001). The SCN clockwork relies on feedback loops in which the CLOCK/BMAL1 heterodimer activates the transcription of three Period (Per1-3), two Cryptochrome (Cry1-2) genes and clockcontrolled genes such as Dbp (albumin D-site binding protein). PER and CRY dimers act as negative regulators of CLOCK/BMAL1 (Albrecht, 2004; Ko and Takahashi, 2006). Per1 and Per2 genes are

\footnotetext{
* Corresponding author. Fax: +33 388456654 .

E-mail address: challet@neurochem.u-strasbg.fr (E. Challet).

${ }^{1}$ These authors contributed equally to this work.

Available online on ScienceDirect (www.sciencedirect.com).
}

the principal actors of SCN resetting (Albrecht et al., 1997; 2001; Zheng et al., 2001).

A number of extra-SCN oscillators have been identified in the mammalian brain (reviewed in Guilding and Piggins, 2007). For instance, rhythmic expression of Perl and Per 2 mRNA is observed in forebrain structures such as olfactory bulbs, piriform and cerebral cortices, hippocampus, paraventricular and arcuate hypothalamic nuclei (Asai et al., 2001; Wakamatsu et al., 2001; Abe et al., 2002; Granados-Fuentes et al., 2004). PER2 expression has also been reported in limbic structures, such as amygdala and bed nucleus of the stria terminalis (Amir et al., 2004; Lamont et al., 2005). Except for the SCN in which the rhythm of PERs follows the mRNA expression by 4-6 h (Field et al., 2000; Mendoza et al., 2007), little is known about the exact timing of both PER1 and PER2 oscillations in forebrain structures. For that purpose, we investigated the daily patterns of PER1 and PER2 expression throughout the forebrain in mice fed ad libitum. Furthermore, to assess the functional significance of PER1 or PER2 oscillations in forebrain structures, we tested the first hypothesis that their molecular clockwork, as assessed by oscillations of Cryl and Dbp mRNA levels, would be specifically altered in Per1 or Per2 mutant mice fed ad libitum.

Whereas light is the principal synchronizer for the SCN, Per oscillations in extra-SCN brain regions can be affected by feeding cues (Wakamatsu et al., 2001; Lamont et al., 2005; AngelesCastellanos et al., 2007). Restricted feeding can produce changes in physiology and behavior which are even more marked in response to hypocaloric feeding (HF) (Challet et al., 2003; Mendoza et al., 2005b; Feillet et al., 2006). Rodents exposed to restricted feeding or $\mathrm{HF}$ express a bout of locomotor activity in the hours preceding access to food. That so-called food-anticipatory activity is supposed to be controlled by a circadian clock outside the SCN (Mistlberger, 1994; Stephan, 2001). Per2 mutant mice do not show foodanticipatory activity, pointing out the essential involvement of Per2 in the anticipation of mealtime (Feillet et al., 2006). Thus, finding alterations in protein level of PER2 in forebrain areas in response to food restriction may help to identify structures relevant for food synchronization. For that purpose, we assessed the expression of both PER1 and PER2 proteins throughout the forebrain of mice challenged with HF. To evaluate the role of PER1 and PER2 in the 
A. WT C3H

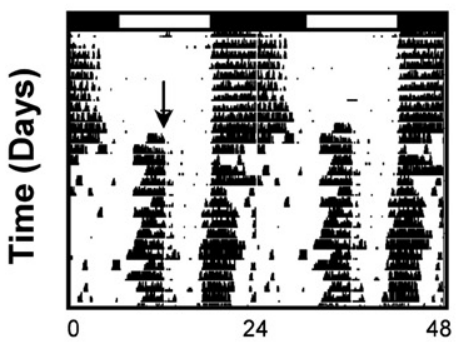

B. WT C57BL $\times 129 S v$

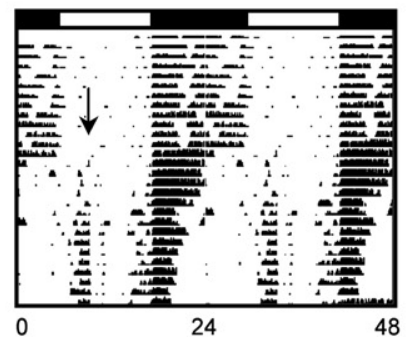

C. Per1-/-

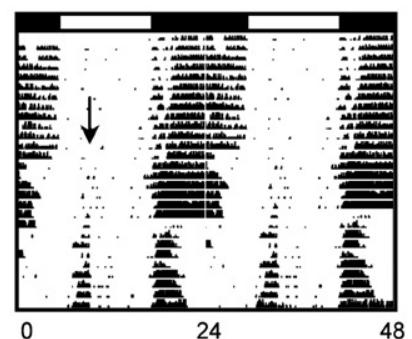

D. Per2 ${ }^{\text {Brbm1 }}$

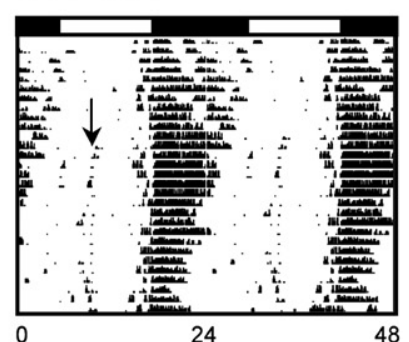

Time (h)

Fig. 1. Daily wheel-running activity in mice fed ad libitum for 10 days and submitted to hypocaloric feeding (arrows) during 3 weeks (A, Wild type C3H mouse; B, wild type C57BL $\times 129$ Sv mouse; C, Per1-/- mouse; and D, Per $2^{\text {Brbm1 }}$ mouse). Locomotor activity is plotted as an actogram with each horizontal line corresponding to two consecutive days and with the second day being double-plotted on the next line. Nighttime is indicated by black bar on top abscissa.

adaptation of forebrain oscillators to food restriction, we hypothesized that HF-induced changes in their clockwork, evaluated via oscillations of Cryl and Dbp expression, would be selectively impaired in Perl or Per 2 mutant mice.

\section{Results}

\section{Daily patterns of wheel-running activity}

All mice fed ad libitum displayed a regular pattern of locomotor activity, with predominant wheel-running activity during nighttime.
When restricted to feed only a hypocaloric diet (HF) during daytime, WT mice (i.e., C3H and C57BL $\times 129 \mathrm{~Sv}$ ) and Perl mutant (Perl-/-) mice developed a daily bout of activity in anticipation of feeding time. By contrast, Per2 mutant $\left(\mathrm{Per} 2^{\mathrm{Brdml}}\right)$ mice did not show foodanticipatory activity (Fig. 1), in accordance with previous findings (Feillet et al., 2006).

PER1 and PER2 expression in the forebrain of mice fed ad libitum

To test whether the expression of PER1 and PER2 was ubiquitous in the forebrain, we performed immunohistochemistry for both

\section{A. PER1}
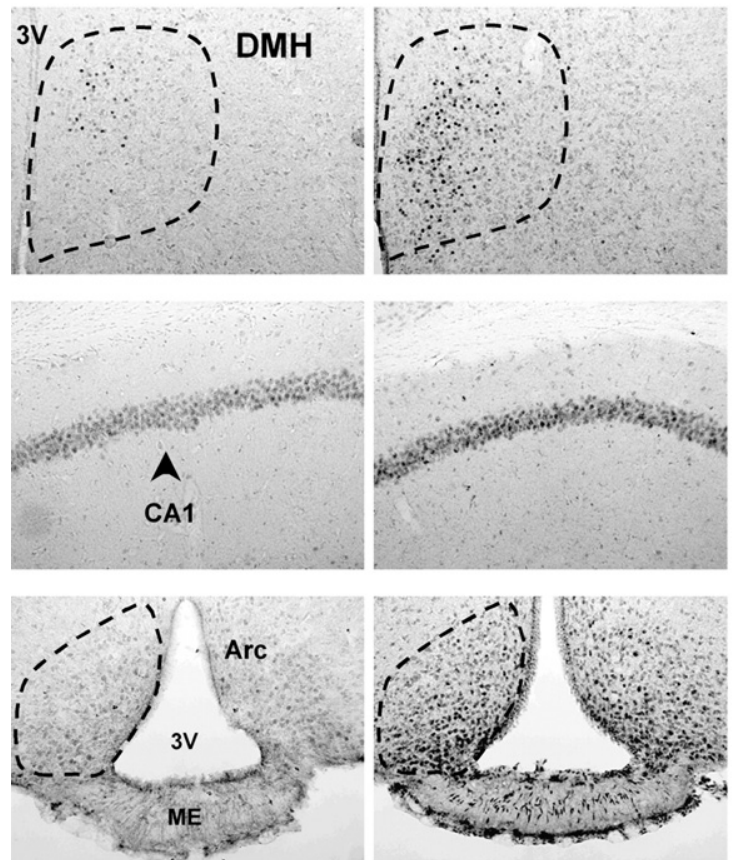

Ad libitum

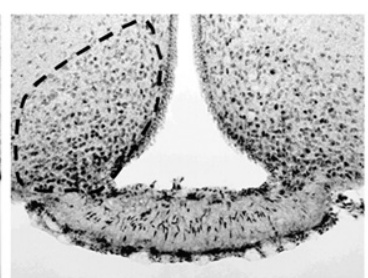

Hypocaloric Feeding
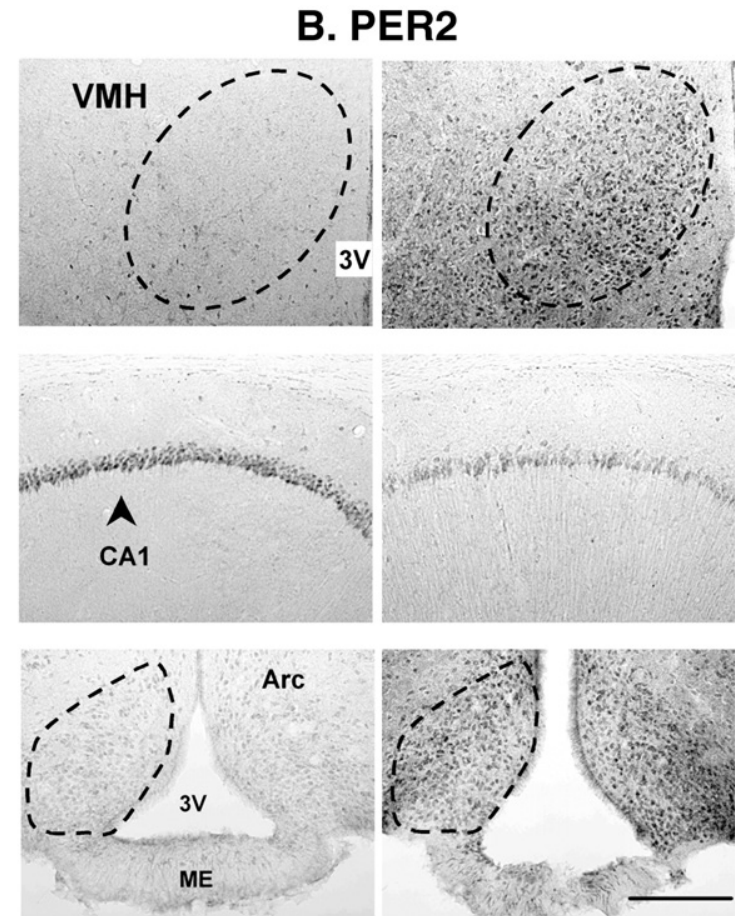

Ad libitum

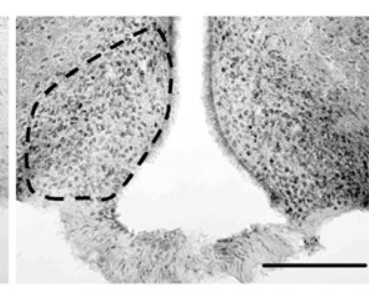

Hypocaloric Feeding

Fig. 2. PER1-immunoreactive cells (left panels, A) in the dorsomedial nuclei of the hypothalamus (DMH; upper left panels), Ammon's horn (CA1; middle left panels) and arcuate nuclei (Arc; lower left panels) and PER2-immunoreactive cells (right panels, B) in the ventromedial nuclei of the hypothalamus (VMH; upper right panels), Ammon's horn (CA1; middle right panels) and arcuate nuclei (Arc; lower right panels). For each structure, feeding conditions are either food ad libitum (left) or hypocaloric feeding (right). 3V, third ventricle; ME, median eminence. Data correspond to ZT8 in DMH, VMH and Arc, and ZT20 in CA1. Scale bar: $200 \mu \mathrm{m}$. 
proteins in mice fed ad libitum. PER1 and PER2 were not both expressed in all structures quantified. In particular, PER1 was expressed alone in aPirC, dST and DMH; it was rhythmic $(p<0.05)$ with fitted peak values at ZT17, ZT19 and ZT9, respectively (Table 1, Figs. 2A and 3A), as assessed with cosinor analysis.

PER2 was expressed alone in BLA, PVN and VMH; it was rhythmic $(p<0.05)$ with daily peaks at ZT21, ZT15 and ZT15, respectively (Table 1, Figs. 2B and 3B). Data obtained for PER2 expression in BLA confirm previous results gathered in rats (Lamont et al., 2005).

Immunoreactive (IR) signals to both PER1 and PER2 were detected in CA1, DG, CEA, PVT and Arc; they were found rhythmic in all cases $(p<0.05$; Figs. 2A, B and 3C). PER1 and PER 2 peaked in phase just before dark-light transition (i.e., ZT22) in CA1 and DG and at ZT16 in the PVT (Figs. 2A and 3C). In both CEA and Arc, PER1 and PER2 IR displayed different patterns, with respective peaks around ZT13/14 and ZT18/19 (Figs. 2A and 3C, Table 1). In CEA, timing of PER2 expression in mice does not match exactly that found in rats (i.e., peak at ZT13; Lamont et al., 2005; Waddington-
Lamont et al., 2007). As a whole, there is a differential expression of PER1 and PER2 in forebrain structures of mice fed ad libitum.

Modifications of PER1 and PER2 expression in the forebrain of mice in response to hypocaloric feeding $(H F)$

Next we studied mice exposed to HF compared to the ad libitum condition. This procedure led to a significant body mass loss (19.4 \pm 0.3 vs. $25.9 \pm 0.5$ g, respectively, $n=24 ; p<0.05$ ). Modifications in PER1 and/or PER2 IR were investigated in the forebrain of mice challenged with HF. In the aPirC of HF mice, a $3 \mathrm{~h}$ phase-advance was detected in the daily oscillation of PER1 compared to the ad libitum condition (Fig. 3A, Table 1).

In $\mathrm{DMH}$, while the phase of daily PER1 expression was unchanged with high values around ZT11, both its mean level and amplitude were increased under HF conditions in comparison with ad libitum values $(p<0.05$; Figs. $2 \mathrm{~A}$ and $3 \mathrm{~A})$. As in $\mathrm{DMH}$, increased level and amplitude of PER1 expression were observed in dST (Fig. 3A, Table 1).

\section{A. Structures expressing PER1}
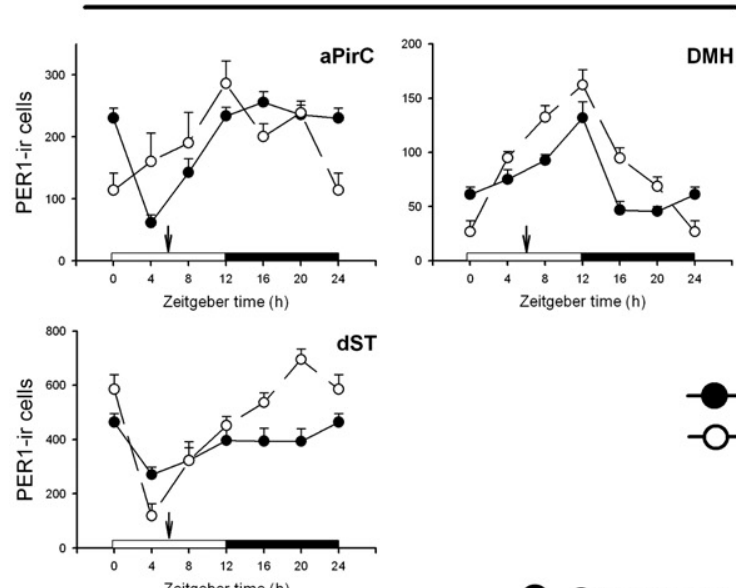

$\mathrm{DMH}$

\section{-O- Hypocaloric feeding}

\section{Structures expressing PER1 and PER2}
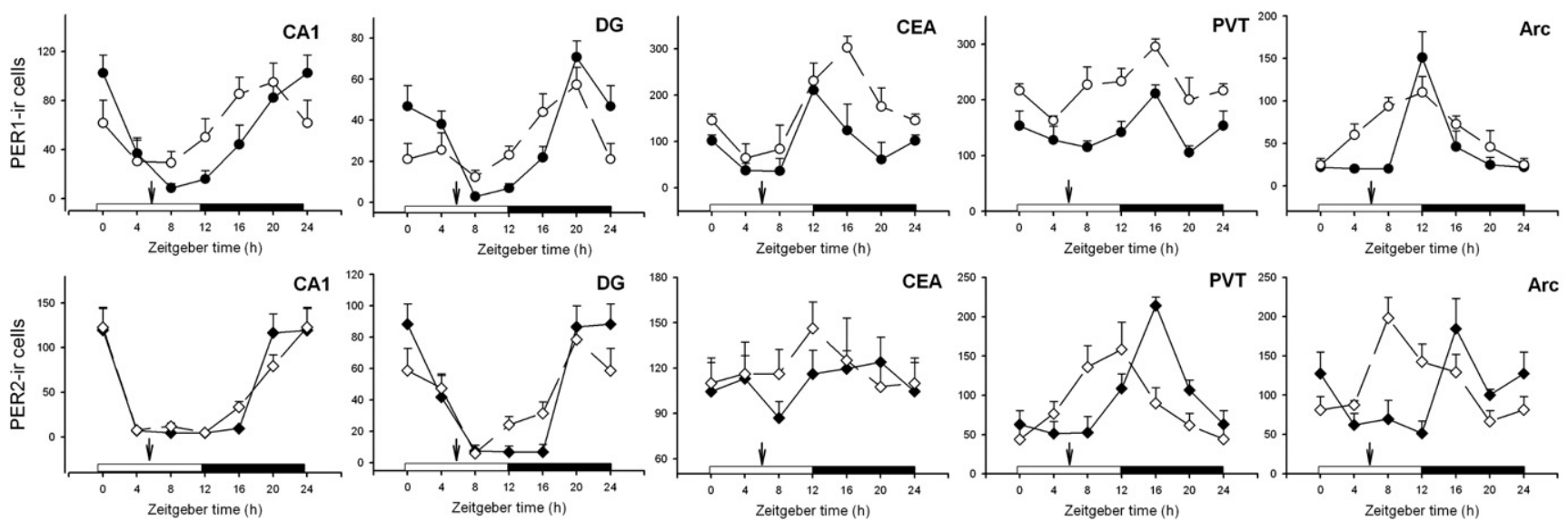

Fig. 3. Daily profiles of PER1 (circles)- and PER2 (diamonds)-immunoreactive cells (mean \pm SEM) in specific forebrain regions of mice $(n=4$ per group and time point) under food ad libitum (black symbols) or hypocaloric feeding (white symbols) conditions. Structures expressing PER1 only (A): anterior piriform cortex (aPirC) and, dorsomedial nuclei of the hypothalamus (DMH) and dorsal striatum (dST); structures expressing PER2 only (B): ventromedial nuclei of the hypothalamus (VMH), paraventricular nuclei of the hypothalamus (PVN) and basolateral amygdala (BLA); structures expressing PER1 and PER2 (C): Ammon's horn (CA1), dentate gyrus (DG), Central amygdala (CEA), paraventricular nucleus of the thalamus (PVT) and arcuate nuclei (Arc). The arrow above the $X$ axis indicates time of feeding. Nighttime is indicated by a black bar on the $X$ axis. 
Table 1

Characteristics of daily oscillations of PER1 and PER2 in the forebrain of mice fed ad libitum or challenged with hypocaloric feeding

\begin{tabular}{|c|c|c|c|c|c|c|c|c|c|c|}
\hline & & \multicolumn{3}{|c|}{ Mean level ( $n$ cells) } & \multicolumn{3}{|c|}{ Amplitude ( $n$ cells) } & \multicolumn{3}{|c|}{ Acrophase (h) } \\
\hline & & $\mathrm{AL}$ & $\mathrm{HF}$ & Comp. & $\mathrm{AL}$ & $\mathrm{HF}$ & Comp. & $\mathrm{AL}$ & $\mathrm{HF}$ & Comp \\
\hline \multirow{6}{*}{$\begin{array}{l}\text { Forebrain structures expressing } \\
\text { PER1 only }\end{array}$} & aPirC PER1 & $193 \pm 9$ & $198 \pm 12$ & $=$ & $85 \pm 12$ & $61 \pm 17$ & $=$ & $17.2 \pm 0.6$ & $13.6 \pm 1.0$ & $+3 \mathrm{~h}$ \\
\hline & aPirC PER2 & $\varnothing$ & $\varnothing$ & & / & l & & / & l & \\
\hline & dST PER1 & $373 \pm 18$ & $451 \pm 24$ & $\uparrow$ & $58 \pm 24$ & $231 \pm 34$ & $\uparrow$ & $18.9 \pm 1.7$ & $18.6 \pm 0.6$ & $=$ \\
\hline & dST PER2 & $\varnothing$ & $\varnothing$ & & / & / & & / & / & \\
\hline & DMH PER1 & $75 \pm 4$ & $96 \pm 4$ & $\uparrow$ & $34 \pm 6$ & $59 \pm 5$ & $\uparrow$ & $9.4 \pm 0.7$ & $10.8 \pm 0.4$ & $=$ \\
\hline & DMH PER2 & $\varnothing$ & $\varnothing$ & & I & / & & 1 & I & \\
\hline \multirow{6}{*}{$\begin{array}{l}\text { Forebrain structures expressing } \\
\text { PER2 only }\end{array}$} & BLA PER1 & $\varnothing$ & $\varnothing$ & & / & l & & / & l & \\
\hline & BLA PER2 & $114 \pm 7$ & $102 \pm 10$ & $=$ & $61 \pm 10$ & l & & $21.7 \pm 0.6$ & l & \\
\hline & PVN PER1 & $\varnothing$ & $\varnothing$ & & / & / & & l & l & \\
\hline & PVN PER2 & $90 \pm 8$ & $91 \pm 8$ & $=$ & $45 \pm 11$ & $35 \pm 11$ & $=$ & $15.3 \pm 0.9$ & $6.6 \pm 1.2$ & $+9 \mathrm{~h}$ \\
\hline & VMH PER1 & $\varnothing$ & $\varnothing$ & & I & 1 & & 1 & I & \\
\hline & VMH PER2 & $151 \pm 15$ & $233 \pm 12$ & $\uparrow$ & $100 \pm 21$ & $120 \pm 17$ & $=$ & $14.7 \pm 0.8$ & $7.5 \pm 0.5$ & $+7 \mathrm{~h}$ \\
\hline \multirow{10}{*}{$\begin{array}{l}\text { Forebrain structures expressing } \\
\text { PER1 and PER2 }\end{array}$} & CA1 PER1 & $48 \pm 4$ & $58 \pm 4$ & $=$ & $46 \pm 5$ & $35 \pm 6$ & $=$ & $22.0 \pm 0.4$ & $18.6 \pm 0.6$ & $+3 \mathrm{~h}$ \\
\hline & CA1 PER2 & $44 \pm 7$ & $43 \pm 6$ & $=$ & $66 \pm 9$ & $54 \pm 8$ & $=$ & $22.0 \pm 0.5$ & $22.0 \pm 0.6$ & $=$ \\
\hline & DG PER1 & $31 \pm 3$ & $30 \pm 3$ & $=$ & $31 \pm 4$ & $19 \pm 4$ & $\downarrow$ & $22.1 \pm 0.4$ & $18.8 \pm 0.7$ & $+3 \mathrm{~h}$ \\
\hline & DG PER2 & $40 \pm 4$ & $41 \pm 0$ & $=$ & $48 \pm 5$ & $31 \pm 4$ & $\downarrow$ & $22.9 \pm 0.4$ & $21.9 \pm 0.5$ & $=$ \\
\hline & CEA PER1 & $95 \pm 13$ & $167 \pm 11$ & $\uparrow$ & $56 \pm 19$ & $109 \pm 16$ & $\uparrow$ & $14.3 \pm 1.3$ & $16.1 \pm 0.6$ & $=$ \\
\hline & CEA PER2 & $111 \pm 4$ & $120 \pm 5$ & $=$ & $13 \pm 6$ & $15 \pm 8$ & $=$ & $18.3 \pm 1.9$ & $12.0 \pm 2.0$ & $+6 \mathrm{~h}$ \\
\hline & PVT PER1 & $142 \pm 8$ & $222 \pm 8$ & $\uparrow$ & $24 \pm 12$ & $44 \pm 12$ & $=$ & $16.1 \pm 1.9$ & $15.1 \pm 1.0$ & $=$ \\
\hline & PVT PER2 & $99 \pm 7$ & $94 \pm 6$ & $=$ & $71 \pm 10$ & $56 \pm 9$ & $=$ & $16.1 \pm 0.5$ & $11.2 \pm 0.6$ & $+5 \mathrm{~h}$ \\
\hline & Arc PER1 & $47 \pm 8$ & $68 \pm 4$ & $\uparrow$ & $47 \pm 12$ & $40 \pm 5$ & $=$ & $12.7 \pm 0.9$ & $11.0 \pm 0.5$ & $=$ \\
\hline & Arc PER2 & $99 \pm 10$ & $117 \pm 8$ & $=$ & $45 \pm 14$ & $56 \pm 11$ & $=$ & $18.9 \pm 1.2$ & $10.1 \pm 0.7$ & $+6 \mathrm{~h}$ \\
\hline
\end{tabular}

AL, food ad libitum; HF, hypocaloric feeding; Comp., comparison between AL and HF; =, no significant difference $(p>0.05) ; \uparrow$, significant increase $(p<0.05) ; \downarrow$, significant decrease $(p<0.05)$; /, lack of significant parameter $(p>0.05)$ in the cosinor analysis; $\varnothing$, lack of immunoreactive signals above background intensity.

For PER2 IR in PVN, there was a large $(9 \mathrm{~h})$ phase-advance $(p<0.05)$, accounting for opposite patterns between HF and ad libitum feeding conditions (Fig. 3B, Table 1). Rhythmic expression of PER2 in the VMH was advanced by $7 \mathrm{~h}$ (peak around ZT8) compared to the ad libitum condition. It was also up-regulated, as shown by higher mean level (Figs. 2B and 3B). In BLA, the daily rhythm of PER2 in HF mice was no longer significant (Table 1), due to an apparent bimodal shape (Fig. 3B).

In Arc and PVT, where both PER1 and PER2 were found to be expressed under ad libitum conditions, the daily patterns of these proteins were still rhythmic under $\mathrm{HF}(p<0.05$, Table 1$)$. In keeping with the observation made in DMH and dST, levels of PER1 were significantly up-regulated in both Arc and PVT due to higher means $(p<0.05$; Figs. $2 \mathrm{~A}$ and $3 \mathrm{C}$, Table 1$)$, whereas the peak time remained unchanged (Arc: ZT13 and PVT: ZT16). PER2 was also found rhythmic in both cases $(p<0.05)$. A large phase-advance was observed in both Arc and PVT where the peak time was advanced by 5 and $6 \mathrm{~h}$, respectively (Figs. 2B and 3C). In CEA, PER 1 expression under HF was globally up-regulated due to an increase in both mean level and amplitude, while PER2 IR was phase-advanced by $6 \mathrm{~h}$ (Fig. 3C, Table 1), in accordance to previous observations in food-restricted rats (Waddington-Lamont et al., 2007). In response to $\mathrm{HF}$, a $3 \mathrm{~h}$ phase-advance of PER1 oscillations was detected in both DG and CA1. For PER2 expression, there is a lack of responsiveness to calorie restriction in those two structures (Figs. 2 and $3 \mathrm{C}$, Table 1).

To sum up, we established that there is a differential expression of PER1 and PER 2 in the forebrain of mice fed ad libitum and that their expression patterns are not uniformly altered by timed HF. In forebrain structures expressing PER1, a small set including aPirC, CA1 and DG displays phase-advanced oscillations of PER $1(\leq 3 \mathrm{~h})$ while in the others, (i.e., CEA, PVT, DMH and Arc), PER1 is upregulated in response to HF. Except for CA1 and DG in which the timing of PER2 oscillations remains unaffected by HF, in other forebrain structures expressing PER2 (i.e., CEA, PVN, PVT, VMH and Arc), PER2 oscillations are phase-advanced by at least $5 \mathrm{~h}$ in response to $\mathrm{HF}$.

Cryl and Dbp expression in WT, Per1 KO and Per $2^{\text {Brdm1 }}$ mutant mice fed ad libitum

We measured Cryl and $D b p$ expression in the forebrain of WT, Perl KO and Per $2^{\text {Brdml }}$ mutant mice fed ad libitum (Figs. 4 and 5) and raised a first hypothesis that differential expression of PER proteins in the forebrain should be mirrored in alterations of the clockwork in respective Per mutant mice under ad libitum conditions. If PER1 or PER2 protein is expressed alone in a structure, then clock mechanisms should be impaired in Perl KO mice or $P e r 2^{B r d m I}$ mutant mice, respectively. If both proteins are expressed, then differential alterations should be observed in each mutant.

In a forebrain structure that was found to express only PER1, i.e., DMH, Cryl was rhythmically expressed in WT mice with a peak at ZT22 under ad libitum conditions (Figs. 4A and 6A, Table 2). In the DMH of Perl-/- mutant mice, the amplitude of Cryl was decreased. Its expression was found to be significantly rhythmic in $P e r 2^{\text {Brdml }}$ mice (with a daily peak at ZT21), but not in Per1-/mutant mice (Fig. 6A). In accordance with PER1 expression detected in the DMH of WT mice, a major alteration of Cryl expression was found in that hypothalamic structure in Perl KO mice. Interestingly, the alterations observed in another PER1 expressing forebrain structure (i.e., aPirC) were comparable to those described above for DMH (Supplemental Fig. 1). We also quantified $D b p$ expression in the DMH. No significant oscillation of $D b p$ was found in all genotypes. The mean level of $D b p$ was significantly reduced in $\mathrm{Per} 2^{\mathrm{Brdm} 1}$ mice compared to WT and Per1 $\mathrm{KO}$ animals (Figs. 4B and 6A). 


\section{Cry1 (WT)}

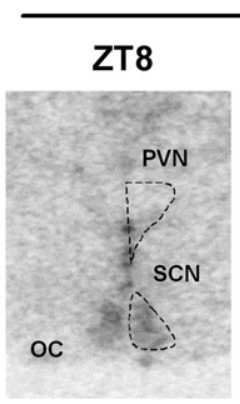

ZT2

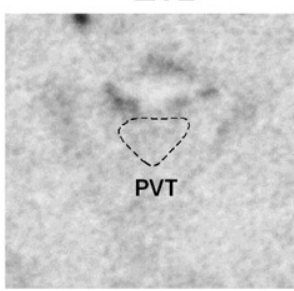

ZT20

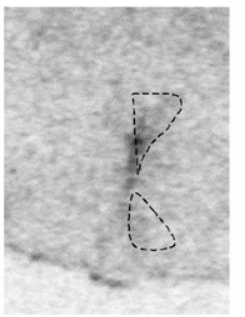

ZT14

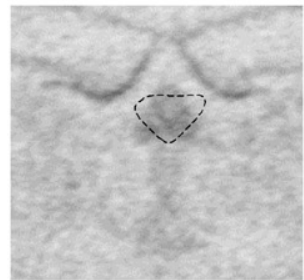

$\mathrm{HF}$

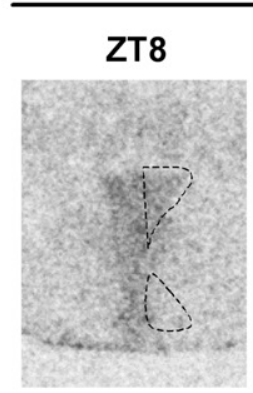

ZT8

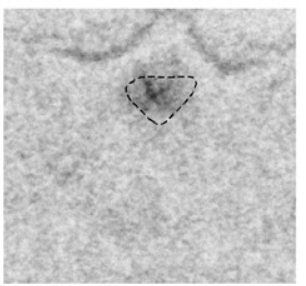

ZT14
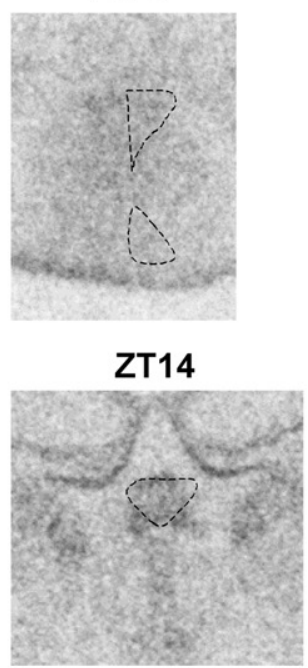

\section{AL \\ Dbp (WT) \\ $\mathrm{HF}$}

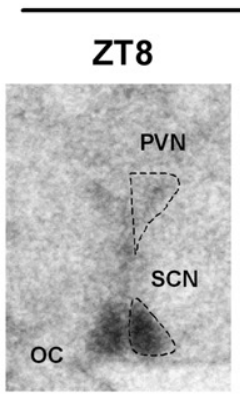

ZT20
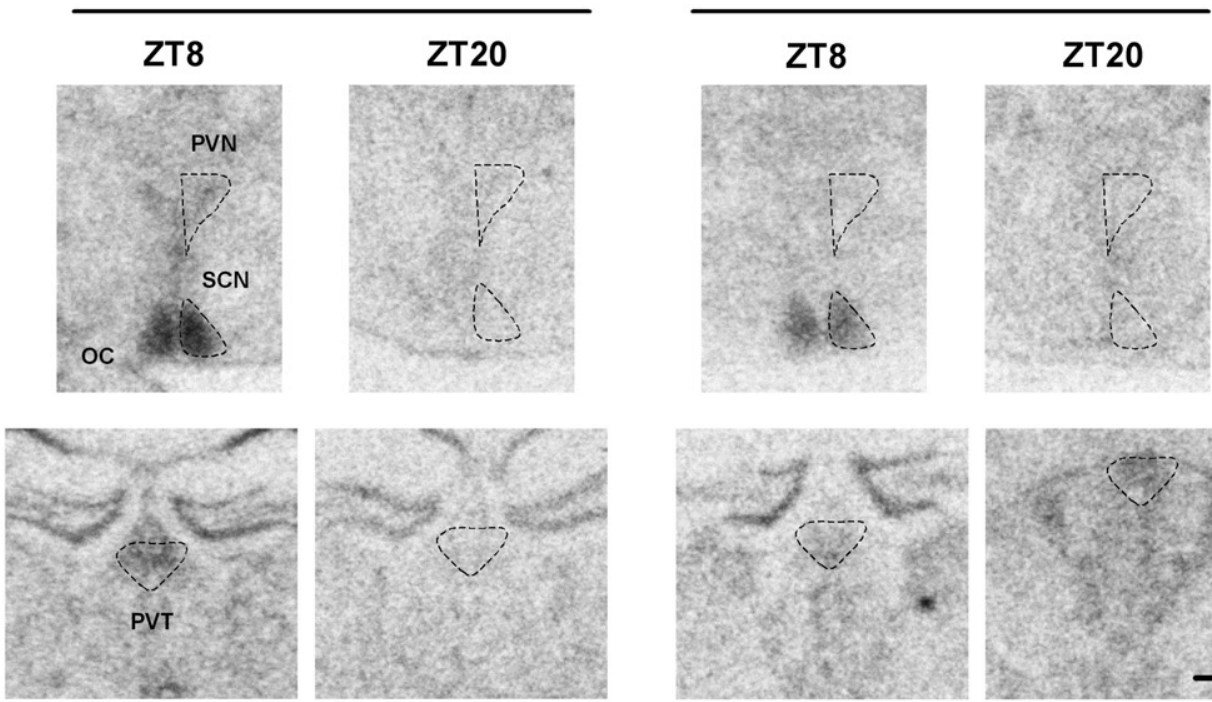

Fig. 4. Autoradiograms of Cryl (A) and Dbp expression (B) at different Zeitgeber times (ZT) in the paraventricular hypothalamic nuclei (PVN), suprachiasmatic nuclei $(\mathrm{SCN})$ and paraventricular thalamic nucleus (PVT) in wild type (WT) mice under ad libitum (AL) or hypocaloric feeding (HF) conditions. Scale bar: $400 \mu \mathrm{m}$.

In a forebrain structure expressing only PER2, i.e., PVN, Cryl expression profiles displayed similar apparent phases between WT and Per1 KO mice (Figs. 4A and 6B, Table 2). According to the cosinor analysis, however, a daily rhythm was significant in WT mice only, with a peak at ZT20 under ad libitum conditions. Note that the shape of the daily profile of Cryl expression in the PVN of Perl mutant mice looks close to the control pattern, albeit with higher values (Fig. 6A). In accordance with the PER2 expression detected in the PVN of WT mice, the expression of Cryl was markedly altered in that hypothalamic nucleus in Per2 mutant mice (Fig. 6B). Differential alterations were also noted in Cryl expression within the VMH of Per2 mutant mice, compared to both
WT and Perl-/- mice (Supplemental Fig. 1). Concerning Dbp expression in the PVN, it was found to be rhythmic only in WT mice and was down-regulated in Per2 mutant mice (Figs. 4B and 6B).

In a forebrain structure expressing both PER1 and PER2 such as PVT, $C r y 1$ profiles were quite different between genotypes, with a daily rhythm for WT and Per2 mutant mice peaking respectively at ZT15 and ZT23 and no significant rhythm for Per1 KO mice (Fig. 6C, Table 2). In CA1 that also expresses both PER1 and PER2, no significant rhythm in Cryl expression was found in any genotype (Supplemental Fig. 1).

To sum up, in mice fed ad libitum, when a structure expressed either PER1 or PER2, alterations in Cryl expression could be 

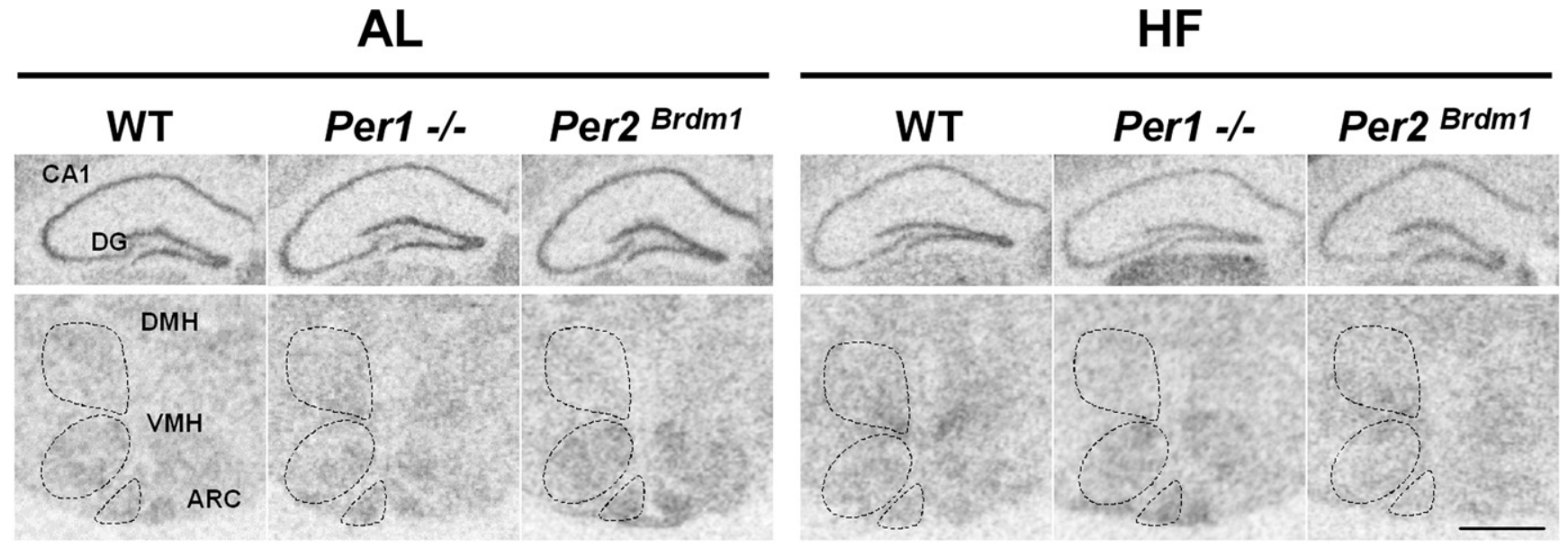

Fig. 5. Autoradiograms of Cryl expression at Zeitgeber time (ZT) 14 in Ammon's horn (CA1), dentate gyrus (DG; top panels), dorsomedial nuclei of the hypothalamus (DMH), ventromedial nuclei of the hypothalamus (VMH) and arcuate nuclei (Arc; bottom panels), in wild type (WT), Perl mutant (Per1-/-) and Per2 mutant $\left(\mathrm{Per}^{\mathrm{Brdml}}\right)$ mice under ad libitum (AL, left) or hypocaloric feeding (HF, right) conditions. Scale bar: $400 \mu \mathrm{m}$.

observed in the corresponding mutant mice compared to WT littermates. By contrast, in structures expressing both proteins, differential alterations were observed in respective mutant mice.

Cryl and Dbp expression in WT, Per1 KO and Per2 ${ }^{\text {Brdml }}$ mutant mice challenged with $H F$

We challenged WT, Perl KO and Per $2^{\text {Brdml }}$ mutant mice with HF that led to a significant loss of body mass compared to ad libitum feeding conditions $(26.5 \pm 1.0$ vs. $31.7 \pm 1.3 \mathrm{~g}, n=15 ; p<0.05)$ in WT as well as in Perl mutant (25.3 \pm 1.1 vs. $31.2 \pm 1.4 \mathrm{~g}, n=15 ; p<0.05)$ and Per 2 mutant mice $(28.3 \pm 1.0$ vs. $33.6 \pm 1.2 \mathrm{~g}, n=15 ; p<0.05)$. No significant difference in body mass was found between genotypes neither under ad libitum food nor HF. We have previously reported that such a HF paradigm elicits a bout of food-anticipatory activity prior to mealtime in WT and Per 1 KO mice, while Per 2 mutant mice did not display food anticipation (Fig. 1). Similar results have been obtained in mice of the same genotypes, but challenged with a temporally restricted food access (Feillet et al., 2006).

Our second hypothesis was that different expression of PER 1 or PER2 in the forebrain should result in differential adaptability of the clock components to nutritional cues. Thus, if PER1 or PER2 protein is expressed alone in a structure, then clock mechanisms should be impaired under HF in Perl KO mice or Per $2^{\text {Brdm I }}$ mutant mice, respectively. If both proteins are expressed in a given cerebral region of WT animals, then differential alterations should be observed in each mutant. To test this, we investigated Cryl and Dbp expression in the forebrain in Per mutant mice under HF conditions.

In a structure that expresses only PER1, i.e., DMH, Cryl expression in WT mice was no longer rhythmic under HF conditions (Fig. 6D, Table 2). Moreover, Cryl profiles in the $\mathrm{DMH}$ were not found rhythmic in Per1 nor Per2 mutant mice (Fig. 6D). While flat in all genotypes, daily expression of $D b p$ was upregulated in response to HF in WT and Perl mutant mice, but not in Per2 mutant mice (Fig. 6D).

In a structure expressing only PER2, i.e., PVN, the daily profile of Cryl expression in WT mice exposed to HF was phaseadvanced by $10 \mathrm{~h}$ (with a peak at ZT10) compared to conditions of food ad libitum (Figs. 4A and 5E, Table 2). No significant rhythm of Cryl expression was detected in Perl KO mice or Per $2^{\text {Brdml }}$ mutant mice. Daily expression of $D b p$ in the PVN was found to be flat in all genotypes, albeit with lower mean values in $P e r 2^{B r d m l}$ mutant mice compared to WT and Perl KO mice (Fig. 6E).

In a structure expressing both PER1 and PER2, such as PVT, profiles of $C r y 1$ were altered under HF in all genotypes (Figs. 4A and $6 \mathrm{~F}), \mathrm{Cry} 1$ expression still showing a narrow but nonsignificant daily peak in WT animals, whereas no rhythm at all could be detected in both mutants (Fig. 6F, Table 2). Daily expression of $D b p$ in the PVT was found to be flat in WT and Perl KO mice, but rhythmic in Per2 mutant mice (Fig. 6F). The mean values of $D b p$ mRNAs in Per $2^{\text {Brdml }}$ mutant mice were lower compared to WT and Perl KO mice (Table 2).

To sum up, there are distinct changes of PER1 and PER2 expression in various forebrain areas of mice challenged with HF. Their differential expression was generally mirrored in the response of $\mathrm{Cry} 1$ expression in $\mathrm{Per}$ mutant mice under HF. In structures that express only PER1 or PER2 in WT animals, Cryl expression was altered respectively in Per1 KO or Per $2^{\mathrm{Brdm} 1}$ mice challenged with HF. In structures that express both PER1 and PER2 in WT mice and were sensitive to nutritional cues (i.e., PVT), HF-induced changes can be modified in both Perl $\mathrm{KO}$ and Per $2^{\mathrm{Brdm} 1}$ mice.

\section{Discussion}

The present study investigated the expression patterns of PER1 and PER2 in the forebrain of mice. The main findings are that PER1 and PER2 are not equally expressed throughout the forebrain of mice with food ad libitum. When a structure expresses either PER1 or PER2, alterations in Cryl expression can be observed in the corresponding Perl or Per2 mutant mice compared to WT littermates. Moreover, forebrain oscillators expressing PER1 and/ or PER2 are differentially sensitive to nutritional cues mediated by daily hypocaloric feeding (HF). Altered responses of Cryl expression were observed in respective Perl or Per 2 mutant mice challenged with $\mathrm{HF}$.

\section{Circadian oscillations in the forebrain of mice fed ad libitum}

A number of extra-SCN oscillators have been identified in the mammalian forebrain (reviewed in Guilding and Piggins, 2007). 
A. Structure expressing PER1
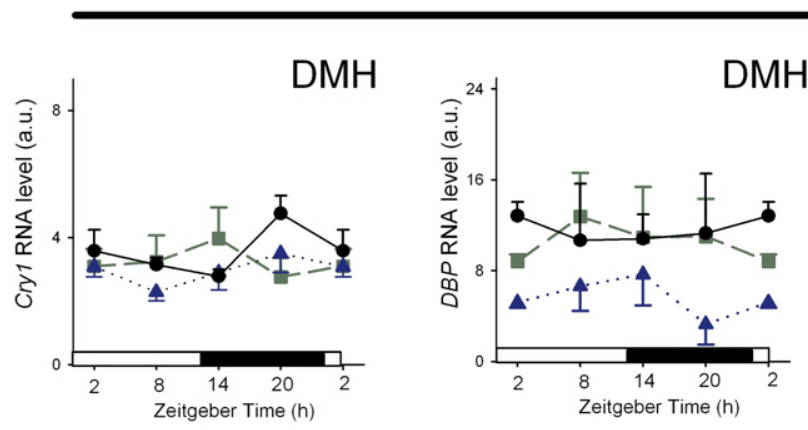

C. Structure expressing PER1 and PER2

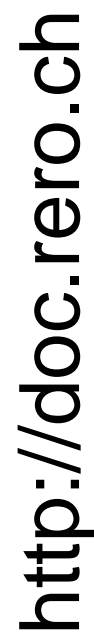
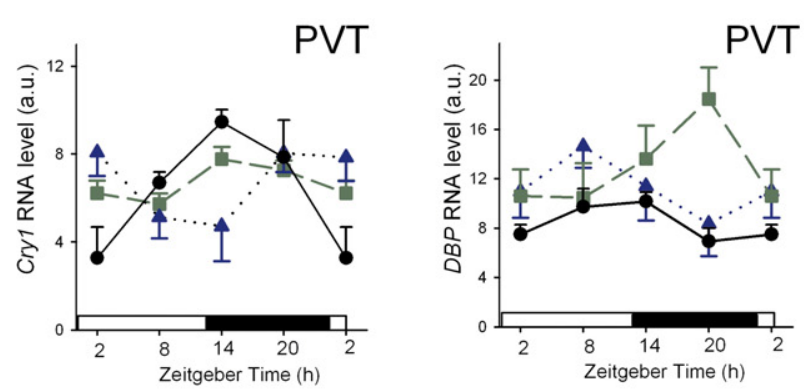

D. Structure expressing PER1
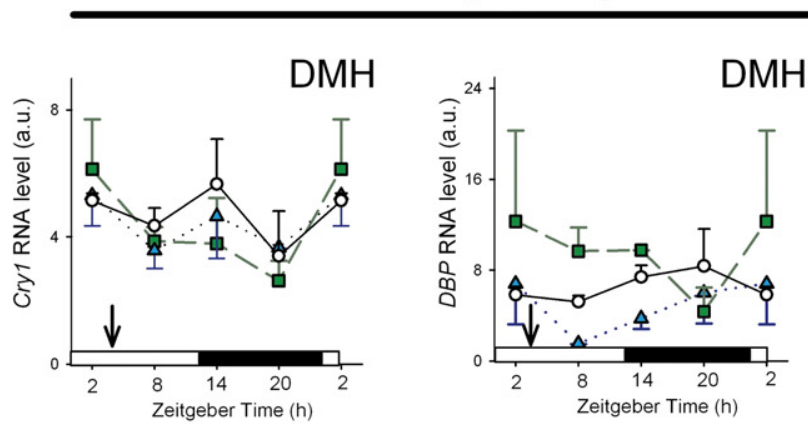

F. Structure expressing PER1 and PER2
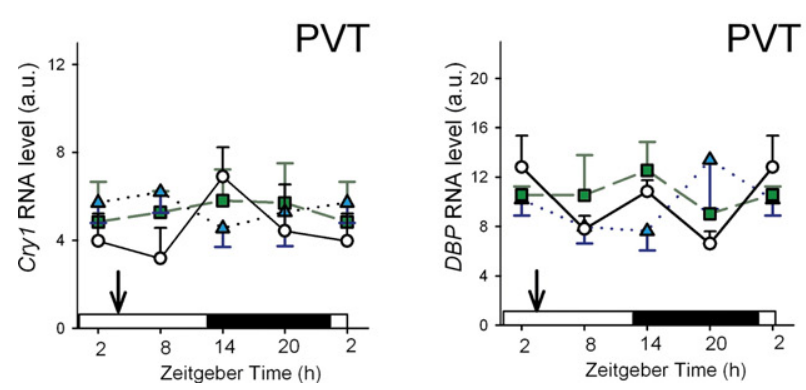

B. Structure expressing PER2
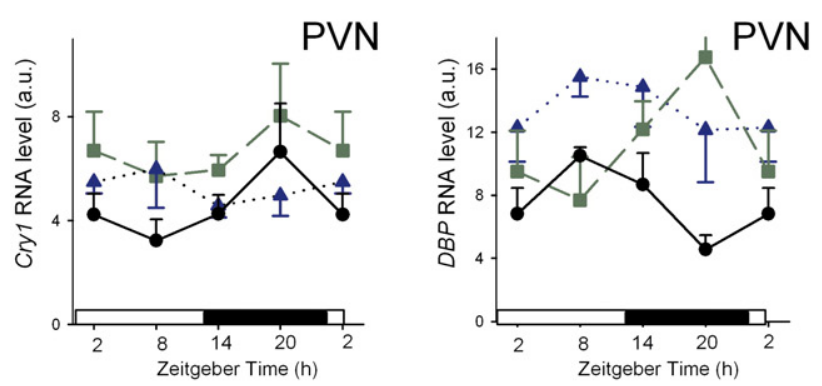

Food ad libitum

- WT

- Per1 -/

- Per2 $2^{\text {Brdm1 }}$
E. Structure expressing PER2
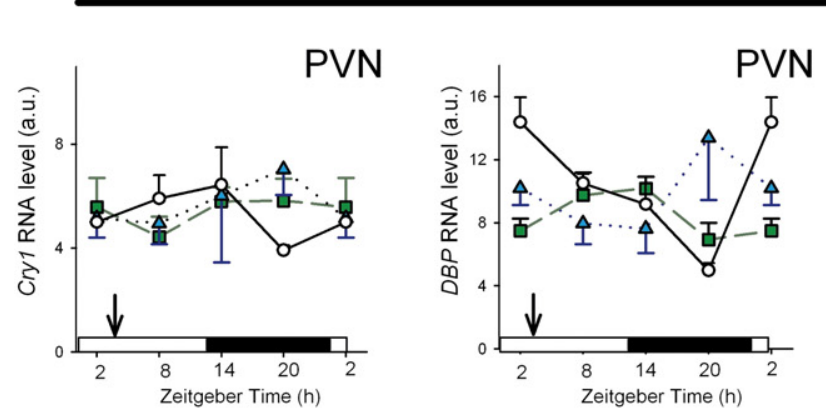

Fig. 6. Daily expression of Cryl gene in the forebrain of mice under ad libitum (A, B and C) or hypocaloric feeding (D, E and F) conditions, as assessed by in situ hybridization. The dorsomedial nuclei of the hypothalamus (DMH) express PER1 only (A and D). The paraventricular nuclei of the hypothalamus (PVN) express PER2 only (B and E). The paraventricular nucleus of the thalamus (PVT) expresses both PER1 and PER2 (C and F). Wild type (WT; black circles, solid lines), Per1 mutant (Per1-/-; green squares, dashed lines) and Per2 mutant $\left(\operatorname{Per} 2^{\text {Brdml }}\right.$; blue triangles, dotted lines) mice $(n=3-4$; means \pm SEM). Data for ZT2 were double-plotted. The arrow above the $X$ axis indicates time of feeding. Nighttime is indicated by a black bar on the $X$ axis. 
Table 2

Characteristics of daily oscillations of Cryl and Dbp mRNA in the forebrain of WT, Per1-/- and Per2 ${ }^{\text {Brdm } 1}$ mutant mice fed ad libitum or challenged with hypocaloric feeding

\begin{tabular}{|c|c|c|c|c|c|c|c|c|c|c|}
\hline & & \multicolumn{3}{|c|}{ Mean level (a.u.) } & \multicolumn{3}{|c|}{ Amplitude (a.u.) } & \multicolumn{3}{|c|}{ Acrophase (h) } \\
\hline & & $\mathrm{AL}$ & $\mathrm{HF}$ & Comp. & $\mathrm{AL}$ & $\mathrm{HF}$ & Comp. & $\mathrm{AL}$ & $\mathrm{HF}$ & Comp. \\
\hline \multirow[t]{3}{*}{ DMH Cryl } & WT & $3.6 \pm 0.2^{\mathrm{a}}$ & $4.6 \pm 0.6^{\mathrm{a}}$ & $\uparrow$ & $0.8 \pm 0.3$ & l & & $21.6 \pm 1.7$ & l & \\
\hline & Perl-/- & $3.3 \pm 0.4^{\mathrm{a}}$ & $4.1 \pm 0.8^{\mathrm{a}}$ & $=$ & / & / & & 1 & l & \\
\hline & $\operatorname{Per} 2^{\text {Brdm1 }}$ & $2.9 \pm 0.2^{\mathrm{a}}$ & $4.2 \pm 0.5^{\mathrm{a}}$ & $\uparrow$ & $0.6 \pm 0.3$ & / & & $20.6 \pm 2.0$ & l & \\
\hline \multirow[t]{3}{*}{ PVN Cryl } & WT & $4.6 \pm 0.6^{\mathrm{a}}$ & $5.2 \pm 0.4^{\mathrm{a}}$ & $=$ & $1.7 \pm 0.8$ & $1.1 \pm 0.5$ & $=$ & $20.1 \pm 1.9$ & $10.2 \pm 1.9$ & $+10 \mathrm{~h}$ \\
\hline & Perl-/- & $6.6 \pm 0.6^{\mathrm{b}}$ & $5.4 \pm 0.6^{\mathrm{a}}$ & $=$ & / & / & & / & / & \\
\hline & $\operatorname{Per} 2^{\text {Brdm1 }}$ & $5.2 \pm 0.3^{\mathrm{ab}}$ & $5.6 \pm 0.7^{\mathrm{a}}$ & $=$ & / & / & & / & / & \\
\hline \multirow[t]{3}{*}{ PVT Cryl } & WT & $6.8 \pm 0.8^{\mathrm{a}}$ & $4.7 \pm 0.7^{\mathrm{a}}$ & $=$ & $3.1 \pm 1.1$ & / & & l & l & \\
\hline & Perl-/- & $6.7 \pm 0.7^{\mathrm{a}}$ & $5.5 \pm 0.7^{\mathrm{a}}$ & $=$ & l & / & & / & / & \\
\hline & $\operatorname{Per} 2^{\text {Brdm1 }}$ & $6.5 \pm 0.7^{\mathrm{a}}$ & $5.4 \pm 0.6^{\mathrm{a}}$ & $=$ & $2.3 \pm 0.7$ & / & & / & / & \\
\hline \multirow[t]{3}{*}{ DMH $D b p$} & WT & $11.3 \pm 1.6^{\mathrm{a}}$ & $6.7 \pm 0.8^{\mathrm{ab}}$ & $\downarrow$ & / & / & & 1 & l & \\
\hline & Perl-/- & $10.9 \pm 1.7^{\mathrm{a}}$ & $8.8 \pm 1.9^{\mathrm{a}}$ & $=$ & l & / & & / & l & \\
\hline & $\operatorname{Per} 2^{\text {Brdm1 }}$ & $5.7 \pm 0.9^{\mathrm{b}}$ & $4.4 \pm 1.5^{\mathrm{b}}$ & $=$ & / & / & & / & / & \\
\hline \multirow[t]{3}{*}{ PVN $D b p$} & WT & $7.6 \pm 0.7^{\mathrm{a}}$ & $7.9 \pm 0.7^{\mathrm{a}}$ & $=$ & $3.1 \pm 0.9$ & / & & $9.1 \pm 1.2$ & l & \\
\hline & Perl-/- & $7.8 \pm 0.8^{\mathrm{a}}$ & $8.5 \pm 0.7^{\mathrm{a}}$ & $=$ & l & / & & l & l & \\
\hline & $\operatorname{Per} 2^{\text {Brdm1 }}$ & $4.8 \pm 0.5^{b}$ & $4.0 \pm 0.4^{b}$ & $=$ & l & / & & / & l & \\
\hline \multirow[t]{3}{*}{ PVT $D b p$} & WT & $8.6 \pm 0.5^{\mathrm{ab}}$ & $9.7 \pm 0.7^{\mathrm{a}}$ & $=$ & $1.9 \pm 0.7$ & / & & $10.9 \pm 1.4$ & l & \\
\hline & Perl-/- & $10.1 \pm 0.6^{\mathrm{a}}$ & $10.7 \pm 1.1^{\mathrm{a}}$ & $=$ & / & / & & / & l & \\
\hline & $\operatorname{Per} 2^{\text {Brdm1 }}$ & $8.0 \pm 0.7^{b}$ & $7.2 \pm 0.5^{\mathrm{b}}$ & $=$ & / & $1.9 \pm 0.6$ & & / & $1.0 \pm 1.4$ & \\
\hline
\end{tabular}

AL, food ad libitum; HF, hypocaloric feeding; Comp., comparison between AL and HF; =, no significant difference $(p>0.05)$; $\uparrow$, significant increase $(p<0.05)$; $\downarrow$, significant decrease $(p<0.05)$; /, lack of significant parameter $(p>0.05)$ in the cosinor analysis. For a given feeding condition (AL or HF) in a given forebrain structure, means lacking common superscripts are significantly different $(p<0.05)$. DMH, PVN and PVT were chosen as examples of forebrain structures expressing only PER1, only PER2 or both PER1 and PER2, respectively.

Here we found that PER1 immunoreactivity (IR) is observed alone in the DMH, aPirC and dST and concomitant with PER2 in the PVT, CA1, DG, CEA and Arc. PER2 IR alone is detected in the PVN, BLA and VMH (Fig. 7). Previous observations have shown a differential expression of Perl and Per2 genes in the forebrain of rodents (Yamamoto et al., 2001; Matsui et al., 2005; Shieh et al., 2005). Nonetheless, some discrepancies exist between these studies and ours: Perl expression was detected in the PVN and VMH (Yamamoto et al., 2001; Matsui et al., 2005), whereas we found no PER1 IR in those areas. Conversely, faint Per2 expression was observed in the aPirC (Matsui et al., 2005; Shieh et al., 2005) and we could not detect PER2 expression in that structure. We did not observe PER1 IR in the PVN, a result consistent with a previous study (Hastings et al., 1999). Posttranscriptional mechanisms can account for the differences observed; for instance, it is possible that Per genes are transcribed, but not translated. Alternatively, a number of post-translational modifications of PER1 or PER2 have been characterized (Gallego and Virshup, 2007; Nishii et al., 2006). Therefore, we cannot fully exclude that post-translational changes that would be specific to certain forebrain oscillators may impair respective binding of the antibodies to PER1 or PER2 used here, preventing immunoreactive signals in those structures. Moreover, in addition to the circadian control of CLOCK-BMAL1 described in the Introduction section, fine-tune regulation of Perl (e.g., by glucocorticoids; Yamamoto et al., 2005) and Per2 (e.g., by heat shock proteins or acute temperature changes; Kornmann et al., 2007) may also account for differential expression of these genes in various cerebral oscillators. Nevertheless, our data on daily patterns of PER2 expression in the BLA and DG in mice fed ad libitum are consistent with previous results obtained in rats (Lamont et al., 2005; Waddington-Lamont et al., 2007). Compared to the PER2 peak observed around ZT12 in the CEA of rats (Lamont et al., 2005) however, maximal expression of PER2 in the CEA occurs later (i.e., ZT20) in mice fed ad libitum.

Thus, forebrain oscillators in mice may not need both PER proteins to keep their clockwork going. In addition, there may be oscillators ticking with different clock hands, depending on their function. This suggests that the PER proteins may have different functions when entering in a clock mechanism. Genes coding for nuclear orphan receptors (ROR), other members of the feedback loops underlying central and peripheral clocks functioning, were found to be unevenly expressed in various peripheral tissues. In that respect, the possibility of differential function for those genes has been evoked (Guillaumond et al., 2005).

As a phase marker of circadian oscillations, we analyzed expression of a clock gene, namely Cryl, in the forebrain of WT mice of the C57BL6 $\times 129 \mathrm{~Sv}$ strain. In the PVN, PVT and DMH, the highest levels of $C r y l$ were observed at night, while those of $\mathrm{Dbp}$, a clock-controlled gene, were observed a few hours earlier (except for DMH in which $D b p$ is not cycling), following comparable phase relationships in expression of the two genes within the SCN clock (Okamura et al., 1999; Yan et al., 2000).

To reinforce our point on a differential expression of PER1 and PER2 in the forebrain of mice fed ad libitum, we tested the first hypothesis that if a structure expresses PER1 and/or PER2, then alterations in clock mechanisms should be observed in respective mutants. We actually confirmed this hypothesis by assessing Cryl expression in the forebrain of WT, Per1 KO and Per 2 mutant mice. Consistently, compared to WT littermates, the pattern of Cryl mRNA was altered in Perl KO mice in those structures that normally express PER1 (i.e., DMH or PVT) in WT mice. The same observation was made in Per2 mutant mice in those structures that normally express PER2 (i.e., PVN or PVT) in WT animals. 


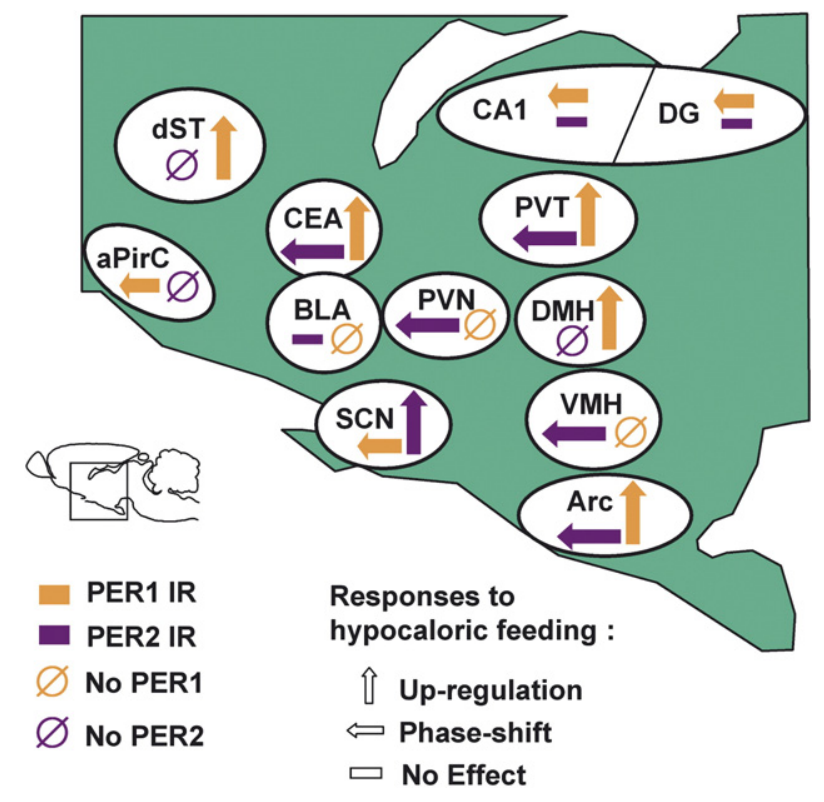

Fig. 7. Schematic sagittal section of a mouse forebrain summarizing differential PER1 (orange) and PER2 (purple) immunoreactivity (IR) under food ad libitum and respective modifications in response to hypocaloric feeding. aPirC: anterior piriform cortex, Arc: arcuate nuclei of the hypothalamus, BLA: basolateral amygdala, CA1: Ammon's horn, CEA: central amygdala, DG: dentate gyrus, DMH: dorsomedial nuclei of the hypothalamus, dST: dorsal striatum, PVN: paraventricular nuclei of the hypothalamus, PVT: paraventricular nucleus of the thalamus, SCN: suprachiasmatic nuclei (data analyzed in Mendoza et al., 2007), VMH: ventromedial nuclei of the hypothalamus.

Previous findings for altered patterns of Cryl and $D b p$ expression in the SCN clock of these mutant mice also fit with these assumptions (Feillet et al., 2006).

\section{Circadian oscillations in the forebrain of mice fed with a hypocaloric diet}

It has been well documented that restricted feeding affects clock gene expression in peripheral tissues and various brain structures (Damiola et al., 2000; Stokkan et al., 2001; Lamont et al., 2005; Angeles-Castellanos et al., 2007; Waddington-Lamont et al., 2007). In the present study, mice were challenged with HF during daytime to assess modifications of daily expression of PER1 and PER2 in the forebrain. Interestingly, daily patterns of PER proteins differentially responded to HF depending on the area considered (Fig. 7). This indicates changes in phase relationships between various forebrain regions under HF compared to ad libitum feeding, suggesting a central dissociation in the rhythms of cerebral regions responding or not to nutritional cues.

In BLA, consistent with our observation in mice fed with HF, PER2 expression has been shown to be transiently decreased at dark-light transition in rats exposed to daytime restricted feeding (Waddington-Lamont et al., 2007). This modest effect together with the lack of shift suggests that BLA is relatively impervious to feeding cues.

In CA1 and DG, HF produced a phase-advance of PER1 IR in keeping with previous studies on Perl mRNA (Wakamatsu et al., 2001) as well as on PER1 levels in food-restricted rats (AngelesCastellanos et al., 2007). This shifting effect $(3 \mathrm{~h})$ for PER1 expression differs from what can be observed in other forebrain regions sensitive to $\mathrm{HF}$, in which PER1 is up-regulated, but not shifted (see below). The amplitude of PER2 expression in DG had been demonstrated to be reduced by restricted feeding (Waddington-Lamont et al., 2007), but no difference in phase was detected in accordance with our observation. Lesions of the hippocampus do not impair expression of food-driven behaviors, such as foodanticipatory activity, elicited by restricted access to food, reinforcing the hypothesis that the hippocampus does not play a key role in food synchronization mechanisms (Mistlberger and Mumby, 1992). This finding fits with the relative insensitivity to $\mathrm{HF}$ of this brain region concerning PER2 expression and to some extent PER1. It is of note that, in the SCN of mice challenged with HF, PER1 expression is phase-advanced, while PER2 is upregulated compared to the ad libitum condition (Mendoza et al., 2007). Also, in the SCN of mice fed with HF, Cryl expression instead of being phase-changed is up-regulated not only in WT, but also in Per1 and Per2 mutant mice (Feillet et al., 2006). It is possible that the hippocampus and BLA remain phase-locked to the SCN and/or the light-dark cycle under HF.

Apart from the hippocampus, BLA and aPirC, all the other forebrain structures quantified here were highly sensitive to $\mathrm{HF}$ signals, leading to major modifications of daily patterns of PER1 and PER2 IR: PER1 was generally up-regulated and PER2 is always phase-advanced in response to HF (Fig. 7). For instance, in CEA, the amplitude of PER1 expression appears to be increased in HF mice, as previously observed in food-restricted rats (Angeles-Castellanos et al., 2007), whereas PER2 pattern was phase-advanced by HF (this study) and restricted feeding as well (Waddington-Lamont et al., 2007). Similar effects on the amplitude of PER1 oscillations were noted for DMH, PVT and Arc, and comparable shifting responses of PER2 were detected for PVN, PVT, Arc and VMH. These different responses to HF considering PER1 or PER2 are in agreement with our first hypothesis about differential function of PER1 and PER2 in the forebrain of mice fed ad libitum. PER2 may be essential for adaptability to variations in feeding cues, whereas PER1 may potentiate or increase reactivity to those cues, without being critical for adaptability per se. This hypothesis is supported by the recent finding that Per2 is critical for the expression of food-driven behaviors, whereas Perl is dispensable (Feillet et al., 2006). Therefore, most forebrain oscillators expressing PER2 would be directly implicated in adaptation to nutritional cues. An example supporting this differential role of PER1 and PER2 is aPirC, the primary olfactory cortex. Ablation of the olfactory bulbs does not abolish food-anticipatory activity (Davidson et al., 2001), indicating that olfactory information is not essential for meal anticipation. It is probable though that it can reinforce feeding cues. Here we find that aPirC expresses PER 1 only and is affected by HF. So it would convey information about food to other area expressing PER2, the synchronization of which would be in turn reinforced.

The DMH had been previously demonstrated to show a de novo expression of Perl and Per 2 mRNA under restricted feeding (Mieda et al., 2006). Moreover, expression of PER2 has been described in the DMH of food-restricted rats (Verwey et al., 2007). Even if we could detect altered patterns of PER1 under HF, no sizeable expression of PER2 in that structure could be seen in any condition. Thus, in the DMH of mice, Per 2 mRNA may actually be transcribed, but not translated. The DMH had been hypothesized to host a putative food-entrainable oscillator controlling foodanticipatory activity. Note however that lesions of the DMH either almost abolish (Gooley et al., 2006) or do not affect (Landry et al., 
2006) expression of food-anticipatory activity. Considering that the DMH do not express PER2 in mice while Per2 seems to be essential for food synchronization, we propose the DMH could be a major output of the food-entrainable oscillator rather than its actual site.

In WT $(\mathrm{C} 57 \mathrm{BL} \times 129 \mathrm{~Sv})$ mice challenged with HF, Cryl expression in the PVN was phase-advanced by $10 \mathrm{~h}$ compared to conditions of food ad libitum. This shifting effect fits well with the 9 $\mathrm{h}$ phase-advance of PER2 oscillation observed for the same structure in mice of another strain $(\mathrm{C} 3 \mathrm{H})$ also fed with HF during daytime (present study). In other structures such as DMH and PVT, Cryl mRNA levels were no longer rhythmic in calorie-restricted mice, precluding assessment of phase shifts. Furthermore, $D b p$ expression in WT mice was down-regulated in the DMH, PVN and PVT in response to HF.

In all structures quantified, compared to WT littermates, the pattern of Cryl expression in response to HF was altered in Perl KO and/or Per2 mutant mice in structures normally expressing PER1 and/or PER2 in WT mice. In the Arc, a region implicated in the regulation of energy metabolism and food intake (Williams et al., 2000), this feature was confirmed under HF only (Supplemental Fig. 1), suggesting that PERs may not be implicated in the Arc functioning under ad libitum conditions. Nevertheless, the Arc seems to be essential for adaptability to restricted feeding. HF induces changes in local cerebral metabolic rate for glucose (LCMRglc) during food-anticipatory activity in the Arc of rats (Pereira de Vasconcelos et al., 2006). Under ad libitum feeding, this area would be synchronized by the SCN and nocturnal feeding, whereas daytime restricted feeding may trigger temporal processes in that area.

The PVT is considered as a relay between circadian and limbic systems (Peng and Bentivoglio, 2004) and mediates the entrainment of the SCN to a palatable meal (Mendoza et al., 2005a), suggesting a role in the regulation of food-anticipatory activity (Nakahara et al., 2004). The LCMRglc increase in the PVT of foodrestricted rats fits with this hypothesis (Pereira de Vasconcelos et al., 2006). Even if PVT lesion does not impair food-anticipatory activity (Landry et al., 2007), our results clearly demonstrate its sensitivity to feeding cues.

As mentioned above, no PER1 IR was detected in the PVN under ad libitum conditions (Hastings et al., 1999). The PVN plays an important role in feeding behavior (Sahu, 2004). Moreover, expression of clock genes and c-FOS in this region is altered during restricted feeding (Wakamatsu et al., 2001; Angeles-Castellanos et al., 2004). LCMRglc in the PVN was found to be specifically affected during food-anticipatory activity in HF rats (Pereira de Vasconcelos et al., 2006). According to our second hypothesis, as the PVN synthesize PER2 whose expression pattern is altered under $\mathrm{HF}$, it may contribute to food-driven behaviors.

Also expressing PER2 only, the VMH are involved in the regulation of energy metabolism and feeding behavior (Pénicaud et al., 1983). In particular, they play a role in sensing hypoglycemia (Yang et al., 1999). Chemical lesions of the VMH reduce behavioral phase changes induced by HF (Challet et al., 1997). Therefore, the VMH can be directly synchronized by feeding cues and in turn influence physiological responses.

In conclusion, our study reveals a differential expression of PER1 and PER2 in the forebrain of mice. Differences of expression may originate in a differential role for both proteins as respective mutants show altered patterns of $C r y 1$ expression in ad libitum and HF conditions. It reinforces the growing hypothesis that there is not one single clock, but a system of multiple brain oscillators
(Roenneberg and Merrow, 2003; Guilding and Piggins, 2007) ticking with different clock hands and differentially sensitive to nutritional cues. It would be interesting to distinguish between motivational and metabolic responses to hypocaloric feeding and their interpretation in each forebrain region. Additional studies by means of real-time reporters and local knock-in or knock-out will reveal the actual function of coupling and/or synchronization between forebrain oscillators.

\section{Experimental methods}

Animals and housing

Adult male $\mathrm{C} 3 \mathrm{H}$ mice (Charles River, Lyon, France) were used for PER1 and PER2 expression analysis. Adult male and female $F_{2}$ homozygous Perl and Per 2 mutant mice and their wild type (WT) C57BL/6 $\times 129$ SvEvBrd littermates were used for Cryl and Dbp mRNA expression analysis. The loss-of-function Perl mutation (Per1-/-) results from deletion of exon 3 to exon 19 of $m P e r l$. The deleted region includes the PAS domain, thus precluding protein dimerization. The Per 2 mutation $\left(\operatorname{Per} 2^{\text {Brdml }}\right)$ was obtained by deleting part of the PAS domain, thus impairing normal protein dimerization. The Per1-/- and Per $2^{\text {BrdmI }}$ mutations are described in detail in Zheng et al. (2001) and Zheng et al. (1999), respectively. All animals were housed singly in cages equipped with a running wheel in a room at $23 \pm 1{ }^{\circ} \mathrm{C}$ under a $12 / 12$ light-dark cycle (LD light 200 lx; darkness 0 lx). Under these lighting conditions, times of day were converted to Zeitgeber times (ZT) in which ZT0 and ZT12 were the onsets of light and darkness, respectively. Food and water were available ad libitum unless otherwise stated.

The two experiments were performed in accordance with the Principles of Laboratory Animal Care (National Institute of Health publication 86-23, revised 1985) and the French national Laws.

The two experiments of the present study were carried out in two strains of mice: $\mathrm{C} 3 \mathrm{H}$ and C57BL6×129Sv. Circadian differences in mouse strains have been clearly characterized in terms of endogenous period and shifting responses to light (Hofstetter et al., 1995; Schwartz and Zimmerman, 1990). However, the endogenous period is similar in both strains $\left(\operatorname{tau}_{\mathrm{C} 3 \mathrm{H}}=23.8 \mathrm{~h}\right.$, see Mendoza et al., 2005b; tau ${ }_{\text {C57BL6 } \times 129 \mathrm{~Sv}}=23.7$ h, see Zheng et al., 1999, 2001), as are their circadian responses to light (for $\mathrm{C} 3 \mathrm{H}$, see Mendoza et al., 2005b; for C57BL6 $\times 129$ Sv, see Albrecht et al., 2001). Thus, except for possible differences in melatonin secretion, we consider that the circadian timing system is comparable in the two strains of mice studied here.

In contrast to temporally restricted feeding paradigms, which do not reduce calorie intake and which allow enough food to be eaten daily, hypocaloric feeding is known to lead to several beneficial physiological actions, such as slowing of ageing, extended lifespan and delayed onset of major age-related diseases in a number of species, including rodents and primates (Hyun et al., 2006; Wolf, 2006). In mice under a light-dark cycle, a daily hypocaloric feeding (i.e., $66 \%$ of animal's daily food intake given each day at the same time), but not temporally restricted feeding, leads to phase advances of behavioral and physiological circadian rhythms controlled by the SCN, whatever the feeding time over the daily cycle (Challet et al., 1998; Mendoza et al., 2005b).

\section{Experimental design for immunohistochemistry}

$\mathrm{C} 3 \mathrm{H}$ mice were randomly divided into two groups: a group of mice fed ad libitum (AL) with a mean spontaneous food intake of $4.6 \pm 0.04 \mathrm{~g}$ and a HF group which was given $66 \%$ (i.e., $3.0 \pm 0.02 \mathrm{~g}$ ) of the daily food intake at midday (i.e., ZT6). Under HF conditions, mice eat their diet in the first $3 \mathrm{~h}$ after food is provided (Mendoza et al., 2005b). If an animal lost more than $20 \%$ of its initial body mass, it was refed accordingly. Three weeks later, ad libitum and HF mice were killed and brains were removed for immunohistochemistry. Sampling was performed at six temporal points with $4 \mathrm{~h}$ intervals (ZT0, ZT4, ZT8, ZT12, ZT16 and ZT20) over a $24 \mathrm{~h}$ cycle ( $n=4$, per temporal point). 
At the selected intervals, animals were killed with an isoflurane overdose and perfused transcardially with $50 \mathrm{ml}$ of $0.9 \%$ saline followed by $50 \mathrm{ml}$ of cold $4 \%$ paraformaldehyde in $0.1-\mathrm{M}$ phosphate buffer (PB; $\mathrm{pH}$ 7.4). Brains were removed, post-fixed (overnight in $4 \%$ paraformaldehyde at $4{ }^{\circ} \mathrm{C}$ ) and transferred to cryoprotectant buffered sucrose solution $(30 \%)$ for $72 \mathrm{~h}$ at $4{ }^{\circ} \mathrm{C}$. Brains were then frozen in isopentane at $-60^{\circ} \mathrm{C}$ and stored at $-80{ }^{\circ} \mathrm{C}$. Serial coronal sections $(30 \mu \mathrm{m})$ through forebrain structures were prepared on a cryostat at $-20{ }^{\circ} \mathrm{C}$ and collected in 0.1 -M phosphatebuffered saline (PBS). Free-floating sections were washed in cold 50-mM Tris-buffered saline (TBS; $\mathrm{pH}$ 7.4; Sigma, St Louis, MO) and incubated in a solution of $3 \%$ of $\mathrm{H}_{2} \mathrm{O}_{2}$ (Sigma) in TBS for $30 \mathrm{~min}$ at room temperature. Brain sections were then rinsed in TBS and incubated for $2 \mathrm{~h}$ in a blocking solution in $3 \%$ normal horse or goat serum and $5 \%$ bovine serum albumine (BSA) in TBS with $0.1 \%$ Triton X-100 (0.1\% TBS-X) followed by $48 \mathrm{~h}$ of incubation in the primary antibody (in $0.1 \%$ TBS-X and horse or goat serum) at $4{ }^{\circ} \mathrm{C}$. We used a goat polyclonal anti-PER1 antibody (1:2000, raised against an epitope mapping the N-terminus of human Per 1; SC-7724, Santa Cruz Biotechnology; Santa Cruz, CA) and a rabbit polyclonal antiPER2 (1:1000, affinity purified raised against an epitope mapping the Cterminus of mouse Per2, Alpha Diagnostic International, San Antonio, TX). Following incubation in the primary antibody, sections were rinsed in TBS$\mathrm{X}$ and incubated for $2 \mathrm{~h}$ at $4{ }^{\circ} \mathrm{C}$ with a biotinylated anti-rabbit $\mathrm{IgG}$ made in goat or anti-goat IgG made in horse (Vector Laboratories, Burlingame, CA), diluted 1:500 with $0.1 \%$ TBS-X. Following incubation with secondary antibody, sections were rinsed in TBS-X and incubated for $1 \mathrm{~h}$ at room temperature with an avidin-biotin-peroxidase complex (Vectastain Standard Elite ABC Kit, Vector Laboratories). Then sections were rinsed two times for $10 \mathrm{~min}$ in TBS and incubated with $0.025 \%$ 3,3-diaminobenzidine (Sigma) with $0.01 \% \mathrm{H}_{2} \mathrm{O}_{2}$ in 50 -mM Tris buffer. After this final incubation, sections were rinsed with TBS, wet-mounted onto gel-coated slides, dehydrated through a series of alcohols, soaked in xylene and coverslipped. The specificity of antibodies was established in mouse brain by preadsorption control experiments. Antibody binding to antigen was blocked by adding the PER1 or PER2 peptides (PER1, sc-7724-P Santa Cruz Biotechnology; PER2 blocking peptide, Alpha Diagnostic International; $1 \mathrm{mg} / \mathrm{ml}$, both diluted 1:100) to the primary incubation solution. The addition of each peptide prevented PER1 and/or PER2 immunostaining (Supplemental Fig. 2).

Sections were viewed using a monitoring CCD video camera with Viewfinder Lite software coupled to a microscope (Leica Microsystems, Rueil Malmaison, France). For the image analysis we used NIH ImageJ software (National Institutes of Health [NIH], Bethesda, MD). For each section, background intensity of staining was determined in an adjacent region devoid of immunoreactive signals. Immunopositive cells were considered positive when their immunostaining exceeded twice the intensity of threshold background. The mean number of immunoreactive nuclei was counted by a researcher blind to the treatment (feeding condition and time) in the dorsal striatum (dST), paraventricular nucleus of the thalamus (PVT), paraventricular nuclei of the hypothalamus (PVN), anterior piriform cortex ( $\mathrm{aPirC})$, dorsomedial nuclei of the hypothalamus $(\mathrm{DMH})$, ventromedial nuclei of the hypothalamus (VMH), arcuate nuclei (Arc), hippocampus (Ammon's horn: CA1 and dentate gyrus: DG) and central (CEA) and basolateral amygdala (BLA) (2-3 sections/level/ animal).

\section{Experimental design for in situ hybridization}

Daily food intake of WT, Perl and Per2 mutant mice was determined during 2 weeks of baseline with food ad libitum. Mice and food were weighed every week. After the baseline period mice were randomly assigned to an ad libitum fed group or to a hypocaloric diet group (HF group), that is, they were provided $66 \%$ of their initial intake close to midday (ZT4) during the following 3 weeks. After 3 weeks of food restriction, mice of each genotype under ad libitum or HF conditions were sacrificed. Sampling was performed at 4 temporal points with 6-h intervals (ZT2, ZT8, ZT14 and ZT20) over a $24 \mathrm{~h}$ cycle ( $n=4$ per temporal point per genotype).

Antisense and sense RNA probes were generated with an in vitro transcription kit (Maxiscript, Ambion, TX). Here we used a riboprobe for $m$ Cryl (GenBank accession number AF156986) and mDbp (GenBank accession number NM016974). Cryl was chosen as phase marker because its rhythmic expression is known to be more reliable than that of other clock genes such as Cry2 (Kume et al., 1999; Okamura et al., 1999). mDbp is a clock-controlled gene coding for a transcription factor called albumin D-site binding protein (DBP) whose transcription shows robust daily oscillations in the SCN (Lopez-Molina et al., 1997; Yan et al., 2000).

Forebrain sections (14- $\mu \mathrm{m}$ thick) were fixed in $4 \%$ phosphate-buffered paraformaldehyde, rinsed twice with PBS and then acetylated twice in $0.1 \mathrm{M}$ triethanol-amine, washed again with PBS and dehydrated in a graded ethanol series. Sections were hybridized overnight with either denatured antisense or sense riboprobe in a humid chamber at $54{ }^{\circ} \mathrm{C}$. Sections were then rinsed with saline sodium citrate, treated with ribonuclease A (Sigma), rinsed with stringency washes of saline sodium citrate and dehydrated in a graded ethanol series. Slices and radioactive standards were exposed for 1 week to an autoradiographic film (Biomax MS-1 Kodak, Sigma). Standards were included in each cassette to verify that the measured values of optical densities were in the linear response range of the film. Densitometric analysis of hybridization signals was performed using ImageJ $(\mathrm{NIH})$ by a researcher blind to the feeding condition, time point and genotype. Before densitometric measures, each forebrain region was first identified on an adjacent section stained with cresyl violet. The optical density of specific signal was calculated by subtracting the intensity of staining background area (defined as a circle of $100 \mu \mathrm{m}$ diameter) measured in the corpus callosum from that of a circle of $100 \mu \mathrm{m}$ diameter measured in various forebrain areas (aPirC, PVT, CA1, DMH, VMH, Arc and PVN for Cryl and PVT, DMH and PVN for $D b p$ ). Measures were made bilaterally (for paired structures) on three slices for each structure and averaged for a given brain. Data were expressed as relative optical density values.

\section{Statistical analysis}

Data are presented as means \pm SEM. The daily patterns of proteins or genes expression were fitted by a non-linear least-squares regression (SigmaPlot software, Jandel Scientific, Chicago, USA). The fitting equation (cosinor) was:

$y=[A+B \cdot \cos (2 \pi \cdot(t-C) / 24)]$

where $y$ is the level of mRNA, $A$ the mean level, $B$ the amplitude of mRNA oscillation, $C$ the acrophase of mRNA oscillation, and $t$ the time (h). Only significant best-fit parameters $(p<0.05)$ were included in this study.

Unpaired Student's $t$-test was used for comparisons of mean level, amplitude and acrophase between AL and HF groups in a given structure for a given genotype. One-way analysis of variance was used to for comparisons of mean level, amplitude and acrophase in a given structure between WT, Perl KO and Per2 ${ }^{B r d m 1}$ mutant mice. Post hoc comparisons were performed with Tukey's test (SigmaStat, Jandel Scientific). The first data points were double-plotted on the figures but were not taken into account for statistical analysis.

\section{Acknowledgments}

We thank Dr. Françoise Eclancher for helpful comments on the manuscript and Dr. Hugues Dardente for providing Cryl clone.

Supported by Swiss-French Funds "Programme d'actions intégrées Germaine de Staël" (U.A. and E.C.), the Swiss National Science Foundation, the State of Fribourg and EUCLOCK (U.A.), the Centre National de la Recherche Scientifique (E.C.), the Institut Servier (J.M.) and the Fondation pour la Recherche Médicale (J.M.). 


\section{References}

Abe, M., Herzog, E.D., Yamazaki, S., Straume, M., Tei, H., Sakaki, Y., Menaker, M., Block, G.D., 2002. Circadian rhythms in isolated brain regions. J. Neurosci. 22, 350-356.

Albrecht, U., 2004. The mammalian circadian clock: a network of gene expression. Front. Biosci. 9, 48-55.

Albrecht, U., Sun, Z.S., Eichele, G., Lee, C.C., 1997. A differential response of two putative mammalian circadian regulators, mPer1 and mPer2, to light. Cell 91, 1055-1064.

Albrecht, U., Zheng, B., Larkin, D., Sun, Z.S., Lee, C.C., 2001. mPer1 and $\mathrm{mPer} 2$ are essential for normal resetting of the circadian clock. J. Biol. Rhythms 16, 100-104.

Amir, S., Lamont, E.W., Robinson, B., Stewart, J., 2004. A circadian rhythm in the expression of PERIOD2 protein reveals a novel SCN-controlled oscillator in the oval nucleus of the bed nucleus of the stria terminalis. J. Neurosci. 24, 781-790.

Angeles-Castellanos, M., Aguilar-Roblero, R., Escobar, C., 2004. c-Fos expression in hypothalamic nuclei of food-entrained rats. Am. J. Physiol. Regul. Integr. Comp. Physiol. 286, 158-165.

Angeles-Castellanos, M., Mendoza, J., Escobar, C., 2007. Restricted feeding schedules phase shift daily rhythms of c-Fos and protein Per1 immunoreactivity in corticolimbic regions in rats. Neuroscience 144 , 344-355.

Asai, M., Yoshinobu, Y., Kaneko, S., Mori, A., Nikaido, T., Moriya, T., Akiyama, M., Shibata, S., 2001. Circadian profile of Per gene mRNA expression in the suprachiasmatic nucleus, paraventricular nucleus, and pineal body of aged rats. J. Neurosci. Res. 66, 1133-1139.

Challet, E., Caldelas, I., Graff, C., Pévet, P., 2003. Synchronization of the molecular clockwork by light- and food-related cues in mammals. Biol. Chem. 384, 711-719.

Challet, E., Pévet, P., Lakhdar-Ghazal, N., Malan, A., 1997. Ventromedial nuclei of the hypothalamus are involved in the phase advance of temperature and activity rhythms in food-restricted rats fed during daytime. Brain Res. Bull. 43, 209-218.

Challet, E., Solberg, L.C., Turek, F.W., 1998. Entrainment in calorierestricted mice: conflicting zeitgebers and free-running conditions. Am. J. Physiol., Regul. Integr. Comp. Physiol. 274, R1751-R1761.

Damiola, F., Le Minh, N., Preitner, N., Kornmann, B., Fleury-Olela, F., Schibler, U., 2000. Restricted feeding uncouples circadian oscillators in peripheral tissues from the central pacemaker in the suprachiasmatic nucleus. Genes Dev. 14, 2950-2961.

Davidson, A.J., Aragona, B.J., Werner, R.M., Schroeder, E., Smith, J.C., Stephan, F.K., 2001. Food-anticipatory activity persists after olfactory bulb ablation in the rat. Physiol. Behav. 72, 231-235.

Feillet, C.A., Ripperger, J.A., Magnone, M.C., Dulloo, A., Albrecht, U., Challet, E., 2006. Lack of food anticipation in Per2 mutant mice. Curr. Biol. 16, 2016-2022.

Field, M.D., Maywood, E.S., O'Brien, J.A., Weaver, D.R., Reppert, S.M., Hastings, M.H., 2000. Analysis of clock proteins in mouse SCN demonstrates phylogenetic divergence of the circadian clockwork and resetting mechanisms. Neuron 25, 437-447.

Gallego, M., Virshup, D.M., 2007. Post-translational modifications regulate the ticking of the circadian clock. Nat. Rev., Mol. Cell Biol. 8, 139-148.

Gooley, J.J., Schomer, A., Saper, C.B., 2006. The dorsomedial hypothalamic nucleus is critical for the expression of food-entrainable circadian rhythms. Nat. Neurosci. 9, 398-407.

Granados-Fuentes, D., Saxena, M.T., Prolo, L.M., Aton, S.J., Herzog, E.D., 2004. Olfactory bulb neurons express functional, entrainable circadian rhythms. Eur. J. Neurosci. 19, 898-906.

Guilding, C., Piggins, H.D., 2007. Challenging the omnipotence of the suprachiasmatic timekeeper: are circadian oscillators present throughout the mammalian brain? Eur. J. Neurosci. 25, 3195-3216.

Guillaumond, F., Dardente, H., Giguere, V., Cermakian, N., 2005. Differential control of Bmall circadian transcription by REV-ERB and ROR nuclear receptors. J. Biol. Rhythms 20, 391-403.
Hastings, M.H., Field, M.D., Maywood, E.S., Weaver, D.R., Reppert, S.M., 1999. Differential regulation of mPER1 and mTIM proteins in the mouse suprachiasmatic nuclei: new insights into a core clock mechanism. J. Neurosci. 19, RC11.

Hofstetter, J.R., Mayeda, A.R., Possidente, B., Nurnberger, J.I., 1995. Quantitative trait loci (QTL) for circadian rhythms of locomotor activity in mice. Behav. Genet. 25, 545-556.

Hyun, D.H., Emerson, S.S., Jo, D.G., Mattson, M.P., de Cabo, R., 2006 Calorie restriction up-regulates the plasma membrane redox system in brain cells and suppresses oxidative stress during aging. Proc. Natl. Acad. Sci. U. S. A. 103, 19908-19912.

Ko, C.H., Takahashi, J.S., 2006. Molecular components of the mammalian circadian clock. Hum. Mol. Genet. 15, 271-277.

Kornmann, B., Schaad, O., Bujard, H., Takahashi, J.S., Schibler, U., 2007. System-driven and oscillator-dependent circadian transcription in mice with a conditionally active liver clock. PLoS Biol. 2007, e34.

Kume, K., Zylka, M.J., Sriram, S., Shearman, L.P., Weaver, D.R., Jin, X., Maywood, E.S., Hastings, M.H., Reppert, S.M., 1999. mCRY1 and mCRY2 are essential components of the negative limb of the circadian clock feedback loop. Cell 98, 193-205.

Lamont, E.W., Robinson, B., Stewart, J., Amir, S., 2005. The central and basolateral nuclei of the amygdala exhibit opposite diurnal rhythms of expression of the clock protein Period2. Proc. Natl. Acad. Sci. U. S. A $102,4180-4184$

Landry, G.J., Simon, M.M., Webb, I.C., Mistlberger, R.E., 2006. Persistence of a behavioral food-anticipatory circadian rhythm following dorsomedial hypothalamic ablation in rats. Am. J. Physiol., Regul. Integr. Comp. Physiol. 290, 1527-1534.

Landry, G.J., Yamakawa, G.R.S., Mistlberger, R.E., 2007. Robust food anticipatory circadian rhythms in rats with complete ablation of the thalamic paraventricular nucleus. Brain Res. 1141, 108-118.

Lopez-Molina, L., Conquet, F., Dubois-Dauphin, M., Schibler, U., 1997. The DBP gene is expressed according to a circadian rhythm in the suprachiasmatic nucleus and influences circadian behavior. EMBO J. 16, 6762-6771.

Matsui, D., Takekida, S., Okamura, H., 2005. Molecular oscillation of Per1 and Per2 genes in the rodent brain: an in situ hybridization and molecular biological study. Kobe J. Med. Sci. 51, 85-93.

Mendoza, J., Angeles-Castellanos, M., Escobar, C., 2005a. A daily palatable meal without food deprivation entrains the suprachiasmatic nucleus of rats. Eur. J. Neurosci. 22, 2855-2862.

Mendoza, J., Graff, C., Dardente, H., Pévet, P., Challet, E., 2005b. Feeding cues alter clock gene oscillations and photic responses in the suprachiasmatic nuclei of mice exposed to a light/dark cycle. J. Neurosci. 25, 1514-1522.

Mendoza, J., Pévet, P., Challet, E., 2007. Circadian and photic regulation of clock and clock-controlled proteins in the suprachiasmatic nuclei of calorie-restricted mice. Eur. J. Neurosci. 25, 3691-3701.

Mieda, M., Williams, S.C., Richardson, J.A., Tanaka, K., Yanagisawa, M., 2006. The dorsomedial hypothalamic nucleus as a putative foodentrainable circadian pacemaker. Proc. Natl. Acad. Sci. U. S. A. 103 , $12150-12155$

Mistlberger, R.E., Mumby, D.G., 1992. The limbic system and foodanticipatory circadian rhythms in the rat: ablation and dopamine blocking studies. Behav. Brain Res. 47, 159-168.

Mistlberger, R.E., 1994. Circadian food-anticipatory activity: formal models and physiological mechanisms. Neurosci. Biobehav. Rev. 18, 171-195.

Nakahara, K., Fukui, K., Murakami, N., 2004. Involvement of thalamic paraventricular nucleus in the anticipatory reaction under food restriction in the rat. J. Vet. Med. Sci. 66, 1297-1300.

Nishii, K., Yamanaka, I., Yasuda, M., Kiyohara, Y.B., Kitayama, Y., Kondo, T., Yagita, K., 2006. Rhythmic post-transcriptional regulation of the circadian clock protein mPER2 in mammalian cells: a real-time analysis. Neurosci. Lett. 401, 44-48.

Okamura, H., Miyake, S., Sumi, Y., Yamaguchi, S., Yasui, A., Muijtjens, M., Hoeijmakers, J.H., van der Horst, G.T., 1999. Photic induction of mPer1 
and mPer2 in Cry-deficient mice lacking a biological clock. Science 286, $2531-2534$.

Peng, Z.C., Bentivoglio, M., 2004. The thalamic paraventricular nucleus relays information from the suprachiasmatic nucleus to the amygdala: a combined anterograde and retrograde tracing study in the rat at the light and electron microscopic levels. J. Neurocytol. 33, 101-116.

Pénicaud, L., Larue-Achagiotis, C., Le Magnen, J., 1983. Endocrine basis for weight gain after fasting or VMH lesion in rats. Am. J. Physiol. 245, 246-252.

Pereira de Vasconcelos, A., Bartol-Munier, I., Feillet, C.A., Gourmelen, S., Pevet, P., Challet, E., 2006. Modifications of local cerebral glucose utilization during circadian food-anticipatory activity. Neuroscience 139 , $741-748$.

Roenneberg, T., Merrow, M., 2003. The network of time: understanding the molecular circadian system. Curr. Biol. 13, R198-R207.

Sahu, A., 2004. Minireview: a hypothalamic role in energy balance with special emphasis on leptin. Endocrinology 145, 2613-2620.

Schwartz, W.J., Zimmerman, P., 1990. Circadian timekeeping in BALB/c and C57BL/6 inbred mouse strains. J. Neurosci. 10, 3685-3694.

Shieh, K.R., Yang, S.C., Lu, X.Y., Akil, H., Watson, S.J., 2005. Diurnal rhythmic expression of the rhythm-related genes, rPeriod1, rPeriod2, and rClock, in the rat brain. J. Biomed. Sci. 12, 209-217.

Stephan, F.K., 2001. Food-entrainable oscillators in mammals. In: Takahashi, J.S., Turek, F.W., Moore, R.Y. (Eds.), Circadian Clocks, Handbook of Behavioural Neurobiology, vol. 12. Kluwer Academic/ Plenum, New York, NY, pp. 223-246.

Stokkan, K.A., Yamazaki, S., Tei, H., Sakaki, Y., Menaker, M., 2001. Entrainment of the circadian clock in the liver by feeding. Science 291, 490-493.

Takahashi, J.S., Turek, F.W., Moore, R.Y., 2001. Circadian clocks. Handbook of Behavioural Neurobiology, vol. 12. Kluwer Academic/ Plenum, New York.

Verwey, M., Khoja, Z., Stewart, J., Amir, S., 2007. Differential regulation of the expression of Period2 protein in the limbic forebrain and dorsomedial hypothalamus by daily limited access to highly palatable food in food-deprived and free-fed rats. Neuroscience 147, $277-285$.
Waddington-Lamont, E., Harbour, V.L., Barry-Shaw, J., Renteria-Diaz, L., Robinson, B., Stewart, J., Amir, S., 2007. Restricted access to food, but not sucrose, saccharine, or salt, synchronizes the expression of Period2 protein in the limbic forebrain. Neuroscience 144, 402-411.

Wakamatsu, H., Yoshinobu, Y., Aida, R., Moriya, T., Akiyama, M., Shibata, S., 2001. Restricted-feeding-induced anticipatory activity rhythm is associated with a phase-shift of the expression of mPer1 and mPer2 mRNA in the cerebral cortex and hippocampus but not in the suprachiasmatic nucleus of mice. Eur. J. Neurosci. 13, 1190-1196.

Williams, G., Harrold, J.A., Cutler, D.J., 2000. The hypothalamus and the regulation of energy homeostasis: lifting the lid on a black box. Proc. Nutr. Soc. 59, 385-396.

Wolf, G., 2006. Calorie restriction increases life span: a molecular mechanism. Nutr. Rev. 64, 89-92.

Yamamoto, S., Shigeyoshi, Y., Ishida, Y., Fukuyama, T., Yamaguchi, S., Yagita, K., Moriya, T., Shibata, S., Takashima, N., Okamura, H., 2001. Expression of the Per1 gene in the hamster: brain atlas and circadian characteristics in the suprachiasmatic nucleus. J. Comp. Neurol. 430, 518-532.

Yamamoto, T., Nakahata, Y., Tanaka, M., Yoshida, M., Soma, H., Shinohara, K., Yasuda, A., Mamine, T., Takumi, T., 2005. Acute physical stress elevates mouse period 1 mRNA expression in mouse peripheral tissues via a glucocorticoid-responsive element. J. Biol. Chem. 280, 42036-42043.

Yan, L., Miyake, S., Okamura, H., 2000. Distribution and circadian expression of dbp in $\mathrm{SCN}$ and extra-SCN areas in the mouse brain. J. Neurosci. Res. 59, 291-295.

Yang, X.J., Kow, L.M., Funabashi, T., Mobbs, C.V., 1999. Hypothalamic glucose sensor: similarities to and differences from pancreatic beta-cell mechanisms. Diabetes 48, 1763-1772.

Zheng, B., Albrecht, U., Kaasik, K., Sage, M., Lu, W., Vaishnav, S., Li, Q., Sun, Z.S., Eichele, G., Bradley, A., Lee, C.C., 2001. Nonredundant roles of the mPer1 and mPer2 genes in the mammalian circadian clock. Cell 105, 683-694.

Zheng, B., Larkin, D.W., Albrecht, U., Sun, Z.S., Sage, M., Eichele, G., Lee, C.C., Bradley, A., 1999. The mPer2 gene encodes a functional component of the mammalian circadian clock. Nature 400, 169-173. 